\title{
UNVEILING THE INFLUENCE OF THE CONSUMER WINE APPRECIATION DIMENSION ON PURCHASING BEHAVIOR
}

by

Pinar Kekec

Graduate Committee:

Supervisor: Dr. Narongsak (Tek) Thongpapanl

Committee Member: Dr. Dirk De Clercq

Committee Member: Dr. Maxim Voronov

\section{A THESIS SUBMITTED IN PARTIAL FULFILLMENT OF THE REQUIREMENTS FOR THE DEGREE OF}

\section{MASTER OF SCIENCE}

in

The Faculty of Graduate Studies

(Marketing, International Business, and Strategy)

BROCK UNIVERSITY

CFebruary 2012 


\section{Table of Contents}

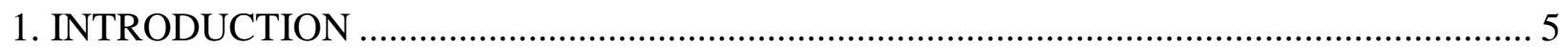

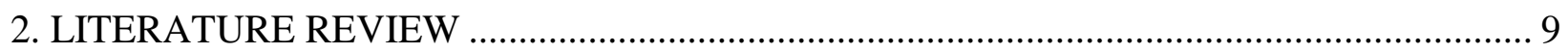

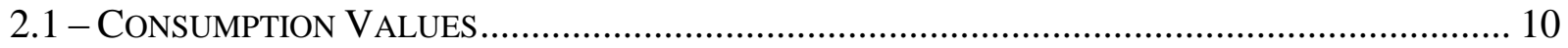

2.2 - Consumption/Usage SituAtion As Conditional V ALUE ......................................... 14

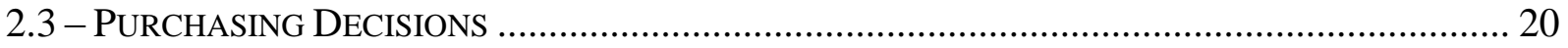

2.3.1 - Willingness to Pay...................................................................................... 23

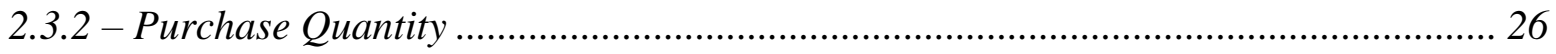

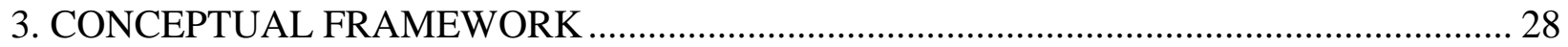

3.1 - CONSUMPTION VALUES \& PURCHASING DECISIONS ................................................. 28

3.2 - CONSUMPTION SITUATION \& PURCHASING DeCISIONS ............................................... 32

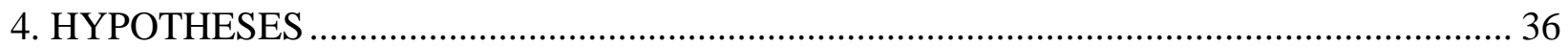

4.1 - The EfFEct of CONSUMER VALUES ON PURCHASING DeCISIONS ................................ 36

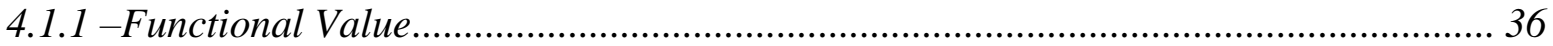

4.1 .2 - Symbolic Value ...................................................................................... 41

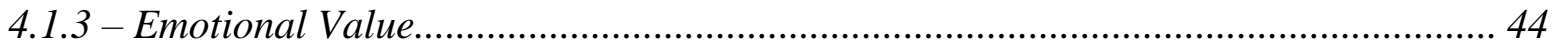

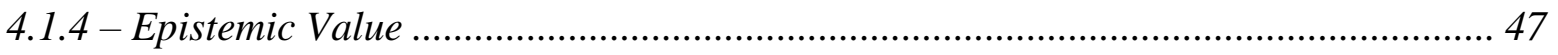

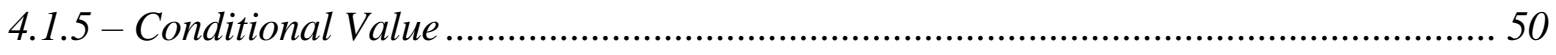

4.2 - The Moderating EFFeCt of Conditional VALUe (RELATED to FormaLIZATION OF

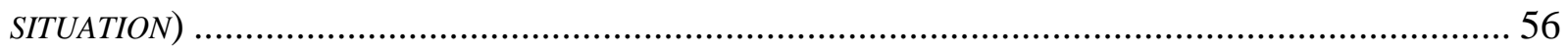

4.2.1 - The Effect of Conditional Value on Functional Value .......................................... 56

4.2.2 - The Effect of Conditional Value on Symbolic Value............................................. 58 
4.2.3 - The Effect of Conditional Value on Emotional Value ................................................. 60

4.2.4 - The Effect of Conditional Value on Epistemic Value................................................... 63

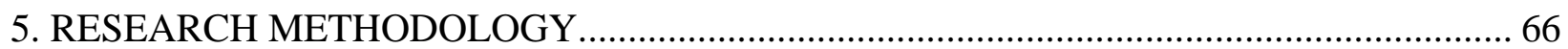

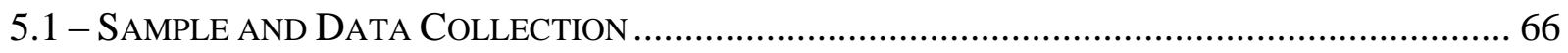

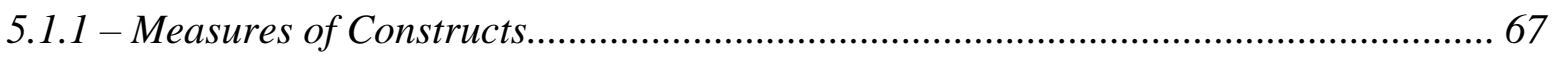

5.1.2 - Assessing the Reliability and Validity of Measures ................................................. 71

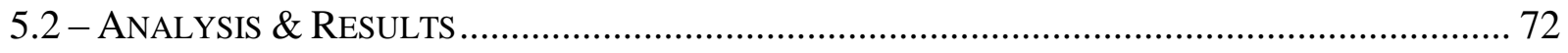

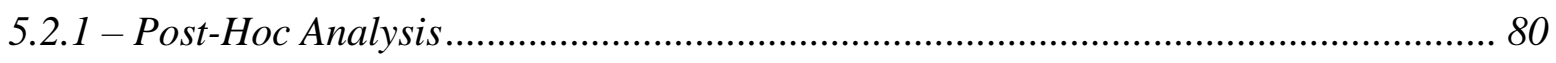

6. DISCUSSION, THEORETICAL AND MANAGERIAL IMPLICATIONS, AND FUTURE

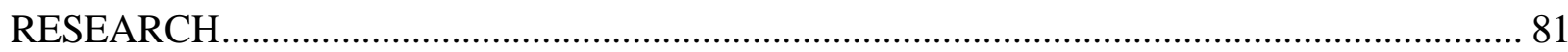

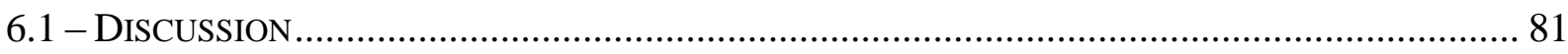

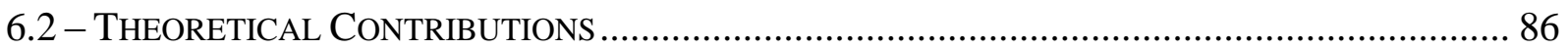

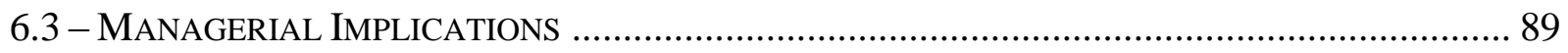

6.4 - FUTURE RESEARCH \& LIMITATIONS ............................................................................... 93

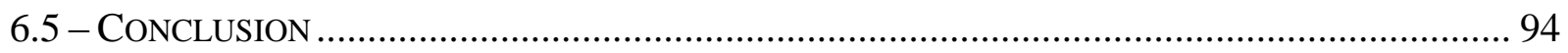

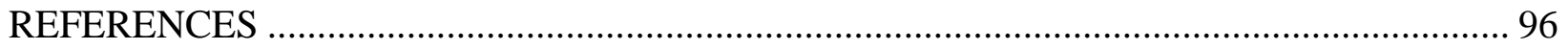




\begin{abstract}
Consumption values and different usage situations have received extensive interest from scholars; however, there is a lack of understanding regarding how these two constructs interact when it comes to the purchase decisions of consumers. This study examines the relationship between consumption values, consumption situations, and consumers' purchasing decisions in terms of their willingness to pay and the purchase quantity. First of all, my model proposes that all four consumption values and different situations have a positive effect on consumers' willingness to pay as well as the quantity they purchase. It also proposes that varying usage situations moderate the effect of consumption values on consumers' purchasing decisions. In my conceptual model, I have also integrated the epistemic and conditional values where there is a gap in the existing literature. Prior literature has isolated the consumption values when studying how they affect consumer behavior and has not examined how consumption situations moderate the relationship between consumption values and purchasing decisions. Also, the existing literature has mostly focused on how consumption values affect purchase intentions, brand loyalty, or satisfaction, whereas my study focuses on purchasing decisions. For my study, the participants were randomly chosen from the general wine consumer population and the age range was between 20 and 75, which included 83 male respondents and 119 female respondents. The data received from my respondents support my hypotheses for the model. In my final chapter, I discuss the theoretical and managerial implications as well as suggestions for future research.
\end{abstract}




\section{ACKNOWLEDGEMENTS}

I would like to acknowledge the support of Dr. Narongsak (Tek) Thongpapanl who encouraged me and helped me with the completion of my thesis. He has been an extremely helpful guide and supervisor. He has made his support available in numerous ways. By drawing on his intellect and experience, I was able to enhance my knowledge and competence. His encouraging comments and ideas helped greatly, providing insight, different perspectives, and guidance on synthesizing my materials. I have been very fortunate to have him as my supervisor, mentor, and advisor.

I am very grateful to Dr. Maxim Voronov for his valuable comments and suggestions. His honest opinions were extremely helpful in broadening my understanding of what else could be examined and how it could be incorporated into my work.

I would like to thank Dr. Dirk De Clercq for his kind and inspiring words and his recommendations. His invaluable comments enhanced my work and motivated me to work nonstop in order to perfect my thesis. It was such a pleasure to work with him.

I thank all of the Business Faculty MIBS Department Staff for their kindness and assistance. It was an honor to be in the same environment as them and they all offered much appreciated insights when I needed them. I thank Brock University for encouraging and helping students through the resources that it provides. I would also like to take this chance to thank my family

for all their support and for being there during the hard times. I am indebted to many of my friends and colleagues who were with me during this journey. They have been an immense help. 


\section{INTRODUCTION}

Probably the most challenging task for marketers is to understand why consumers buy what they buy and avoid other purchases. To understand consumers' predictions, judgments, and choice outcomes, researchers must first determine which inputs are required and what determines the weight of those inputs in the decision-making process (Lynch Jr. \& Zauberman, 2007). The factors that influence purchasing decisions are the layout of the store (Inman, Winer \& Ferraro, 2009), whether the product is made locally or globally (Steenkamp \& Jong, 2010), what external sources were referenced (Putsis \& Srinivasan, 1994), whether the decision was made collaboratively or individually (Munsinger, Weber, \& Hansen, 1975; Spiro, 1983), which emotions or peculiar beliefs contributed to the decision (Sweeney, Soutar, \& Mazzarol, 2008; Watson \& Spence, 2007; Penz \& Hogg, 2011; Bearden \& Etzel, 1982; Kramer \& Block, 2010), and whether the consumer is in the presence of other people, such as friends, family members, coworkers, or just other customers (Luo, 2005).

The factors listed above are well-known and commonly studied subjects; however, there is currently insufficient understanding of the effect of consumption values and consumption/usage situations on purchasing decisions and how values, situational factors, and purchasing decisions are related. Therefore, my study will contribute to the existing literature by providing a framework that integrates these three variables and will show the interplay between them.

The concept of perceived value has been studied by many scholars in the past and is still receiving extensive research interest at present (Sanchez-Fernandez \& IniestaBonillo, 2007). Some have suggested that the perceived value was just a trade-off 
between 'give' and 'get' (Zeithaml, 1988, Tellis \& Gaeth, 1990), whereas others considered this view as too narrow to explain the complexities of consumer purchasing decisions (Sheth, Newman, \& Gross, 1991; Babin et al., 1994; Woodruff \& Gardial, 1996; Lapierre, 2000; Parasuraman \& Grewal, 2000). The types of consumer values have been separated into two different streams: 1) the uni-dimensional stream and 2) the multidimensional stream. Uni-dimensional approaches have mostly studied the trade-off perspective in order to analyze consumer decision-making (Sanchez-Fernandez \& Iniesta-Bonillo, 2007; Pendleton, 2009), whereas the multi-dimensional approach has taken the complex nature of consumers into account and included both utilitarian values, which describe the simple perspective of "give" over "get," and hedonic values, which describe the more complex perspective of what a consumer may think of how others perceive the product, whether the product reminds the person of a memory, or whether the product is considered unique. For instance, Triandis' (1994) research identified three factors that affect social behavior: subjective culture, past experiences, and the behavioral situation. Subjective culture, representing the categorizations, associations, norms, and values in a culture (Triandis, 1994), is expected to influence the perception of the product, the outcome of the purchasing decision, and habits through customs and past experience. In my paper, I expect to see a similar interaction between consumption values and purchasing decisions. By integrating the concepts of utility and hedonic values, several authors generally agree on five consumption value dimensions (Sheth, Newman \& Gross, 1991; Mathwick, Malhotra \& Rigdon, 2001). These are functional, social, emotional, epistemic, and conditional values that consumers may assign to products. Since consumers are likely to weigh the value of certain items, marketers need to 
understand what consumers value the most and how to communicate the value of a product better (Sweeney \& Soutar, 2001). Osgood, Suci, and Tannenbaum (1957) suggest that the hedonic and utilitarian aspects of attitudes may be related, whereas Sheth, Newman, and Gross (1991) suggest that the five consumption values are independent. In my framework, these five values will be taken independently as per Sheth, Newman, and Gross (1991) because when consumers are making a purchasing decision, generally they base their decisions on a value that outweighs the others.

Prior research suggests that the usage situation of a product influences the choices of consumers (Kaltcheva \& Weitz, 2006). When consumers evaluate a product, they will likely consider the specific consumption situation it will be used in as well as the message the product will deliver. In such cases, every individual would have a specific goal to satisfy and base their purchasing decisions on reaching that goal (Heitmann, Lehmann, \& Herrmann, 2007). On the road to satisfying that goal, every factor in a specific situation will shape their perceptions of products. In varying usage situations, the reason to purchase a product may change or the structure of a specific situation may change the end result (Belk, 1975; Luo, 2005). The outcome of such decisions will depend on what a consumer wants from the product, how the product will be used, and how the consumer wants to benefit from the decision in the end (Huneke, Cole, \& Levin, 2004). Therefore, a consumption situation will shape how consumers perceive a product and how that perception may affect their purchasing decision.

The effect of consumption values on consumers' purchasing decisions and the extent to which certain usage situations affect how consumers assign values to products will be studied in this paper. The lack of prior research on the interplay between these 
constructs makes it clear that there is a knowledge gap in this complex topic of consumer purchasing decisions. My study contributes to the existing literature by shedding more light on how consumers make certain decisions in different scenarios. This paper contributes to the existing literature in three distinct areas: First, prior researchers could not integrate two of the consumption values into their conceptual models because of the product types they chose to study. My study will address this gap by integrating the epistemic and conditional values of products. The reason I expect that my model will work and show the effects of epistemic and conditional values on purchasing decisions is that, I am using "wine" for my study, and wine is an experiential product (De Pelsmacker, 2005; Mueller, Lockshin, \& Louviere,2010) which is closely related with epistemic value. In addition, wine products could be used for personal or non-personal reasons, such as gift-giving situations; therefore, my study can integrate the conditional value and show how it affects purchasing decisions. Secondly, I contribute to the existing literature by analyzing the moderating effect of consumption situations on consumption values. Prior research has not integrated usage situations and consumption values in a conceptual model. My study will show the interaction effect and I hope to shed some light on consumers' complex purchasing decisions. Lastly, my study contributes to the literature by studying purchasing decisions as the dependent variable. Prior studies have focused largely on purchase intentions (Wang, 2010) and brand loyalty (Khalifa, 2004). In my study, I will focus on the actual purchasing decisions of consumers in terms of willingness to pay and purchase quantity.

The organization of this paper as follows: First, I will introduce the five consumption values. The consumption values section will be mainly based on how Sheth, 
Newman and Gross (1991) identified these variables and how other scholars have used this model to test their hypotheses. Next, I will explain what I mean by consumption/usage situations. I will briefly review the previous research on the effect of situational components on purchasing decisions. Next, I will form my hypotheses, and then I will analyze my data and present my results from the empirical study. In the final chapter, I will discuss my results, provide theoretical contributions and managerial implications, and propose future research directions.

\section{LITERATURE REVIEW}

The purchasing behavior of consumers has been a key concept in academic papers. Previous studies have tried to explain what affects a consumers' choice of a product. Some literature has argued that situational factors affect purchase behavior (Belk, 1975) and some other scholars have tried to identify the effect of consumers' value systems on these behaviors (Kropp, Lavack, \& Silvera, 2003; Shukla, 2009; White \&Dahl, 2006).These studies made it clear that psychological, sociological, and situational influences all have an impact on the purchasing decisions of consumers. Psychological influences refer to the internal, personal, and private factors that play a role in a consumer's decision. Psychological influences on decisions may be the result of cultural influences; physical drives such as thirst, hunger, etc., which are related to functional value associated with the product; self-image; social factors such as purchasing a T-shirt because their favorite singer has one, which is related to the symbolic value of a product; and finally, the learning experience of the consumer may also influence their decision, which is related to the epistemic value of a product. Sociological influences refer to the external and social factors that are outside a consumer's control. Sociological influences recognize the cultural impact, customs, heritage, and folkways in determining the final 
outcome (Jonassen, 1959), all of which are related to the emotional value of a product. Situational factors refer to the specific environmental circumstances that an individual is in, at a particular moment (Belk, 1975); thus, they will affect how an individual perceives the product and that is related to the conditional value of a product.

The following section will describe each construct and will discuss previous studies that are relevant to consumption values, consumption/usage situation, and purchasing decisions.

\section{1 - Consumption Values}

The concepts of values are generally described as "1) concepts or beliefs, 2)about desirable behaviors and/or end states, 3) that go beyond specific situation, 4) guide the selection or evaluation of events and behavior, and 5) are ordered by a certain hierarchical importance" (Grunert \& Scherhorn, 1990, pp. 97-98). Values play a vital role in the purchasing decisions of consumers because they are usually shaped by consumers' characteristics, buying power, and wants and needs (Morton, 2000). A better understanding of values can potentially provide substantial insights into consumer purchasing behavior.

Rokeach (1973) viewed a value as "a centrally held, enduring belief which guides actions and judgments across specific situations and beyond immediate goals to more ultimate end-states of existence that a particular mode of behavior or end-state of existence is preferable to opposite modes or end-states" (p. 5), whereas Zeithaml's (1988) definition of values is "the consumer's overall assessment of the utility of a product based on perceptions of what is received and what is given" (p. 14). Zeithaml's (1988) view on values is uni-dimensional (Sanchez-Fernandez \& Iniesta-Bonillo, 2007). In my study, I will be studying consumption values which include both the utilitarian and hedonic 
dimensions (Holbrook, 1996 ; Babin et al., 1994; Woodruff \& Gardial, 1996; Mattsson, 1992) where utilitarian stands for the "give" over "get" perspective and hedonic gives the concept another dimension in terms of the product's image, the feelings a consumer receives from the product, or the uniqueness of the product.

Consumers' value structures play a vital role in shaping their decisions regarding a certain product. Values are a more comprehensive measure of customers' evaluation of a product because consumers tend to employ internal analysis by relying on the values they may have held before analyzing the physical product (Bolton \& Drew, 1991). Since consumers will likely try to align their decisions with their attitudes and values, they will try to optimize their purchasing decisions based on five main consumption values so that they are satisfied with their results (Posavac, Herzstein, \& Sanbonmatsu, 2003). When alternatives are essential, consumers, without difficulty, can review the options and make a value-consistent choice, but when consumers have little expertise in a product category, they are more likely to seek the opinions of others who are demographically similar (Posavac, Herzstein, \& Sanbonmatsu, 2003; De Bruyn \& Lilien, 2005). The reason for this is that consumers tend to believe that demographically similar people will hold the same values and attitudes towards the alternatives, and the decisions of those people will guide the actual consumer's behavior.

The reason I study five consumption values in my paper is that past research has not fully captured the epistemic and conditional values in the context of consumption values and because they are important aspects of personal identity and personality differences (Luna \& Gupta, 2001). Values shape a consumer's attitudes toward a product, which in turn may affect their purchasing decisions (Udell, 1965). The value a customer 
assigns to a product changes across consumer segments and cross-nationally (Overby, Gardial, \& Woodruff, 2004). The difference values that consumers may hold regarding a product may arise from differences in cultures, social groups, or ethnic backgrounds because consumers' value systems are developed over time as consumers are socialized into a particular group. Sheth, Newman, and Gross (1991) have stated that "functional values are the perceived utility acquired from an alternative's capacity for functional utilitarian, or physical performance" (p. 160). Babin et al. (1994) have also stated that functional value consists of the job the product needs to do, its performance, and the result-oriented dimensions. A consumer will likely choose one alternative over another if he/she is involved in utility maximizing, such as deciding to purchase based on the price, shape, health concerns, and so on. In this context, functional values received from the product will be more dominant than other values.

Symbolic values are "the perceived utility acquired from an alternative's association with one or more specific social groups" (Sheth, Newman,\& Gross, 1991, p. 161). Symbolic value also demonstrates consumers' perception of an item and how well it fits with special reference groups (White \& Dahl, 2006), signals status (Shukla, 2009), or sends a message (Park, Jaworski, \& MacInnis, 1986). If a consumer is presented with the same alternatives, he/she may pick different options based on the message the product signals. He/she may pick the well-known brand, or the product that his/her peers are using, or the product made by a socially responsible company. Therefore, symbolic values among people act as an influential factor because consumers tend to want to fit in with their society and thus will purchase what the society demands in order to conform to social standards (Luna \& Gupta, 2001; Shukla, 2009). 
Emotional values are "the perceived utility acquired from an alternative's capacity to arouse feelings or affective states" (Sheth, Newman,\& Gross, 1991, p. 161). Previous researchers have shown that emotions influence consumer purchase decisions (Mizerski \& White, 1986; Burnett \& Lunsford, 1994) and positive emotions are correlated with purchasing decisions (Park, Kim, \& Forney, 2006). If a person is presented with similar alternatives, he/she may go with the one that he/she experienced before, or the one that makes him/her more comfortable. Whatever the reason behind the purchase decision, as soon as the product evokes a certain feeling, then the emotional value of the product will be dominant over the other values, especially in contexts where the hedonic tone of consumption may trigger pleasant memories which could lead consumers to build positive attitudes toward a product (Posavac, Herzstein, \& Sanbonmatsu, 2003; Dube, Cecile-Cervellon, \& Jingyuan, 2003).

Epistemic values are "the perceived utility acquired from an alternative's capacity to arouse curiosity, provide novelty, and/or satisfy a desire for knowledge" (Sheth, Newman,\& Gross, 1991, p. 162). If consumers are bored with their current choice of product and they are willing to explore new things, then they will likely pick another similar product or pick something completely different. Therefore, in this context, epistemic values are in play when the product is satisfactorily providing novelty and a new experience for the consumers.

Lastly, conditional values are "the perceived utility acquired by an alternative as the result of the specific situation or set of circumstances facing the choice maker" (Sheth, Newman, \& Gross, 1991, p. 162). In general, products deliver conditional value when consumers are in a specific situation such as birthdays, anniversaries, or even when 
they are in an emergency situation. The level of formality in such situations is also an important factor that determines how consumers perceive the value of the product. For instance, consumers will likely call an ambulance if there is an emergency; or they will likely purchase a more expensive bottle of wine if they are invited to their boss's house. Therefore, the perceived conditional value of a product will affect their purchase decisions when they are in a specific circumstance.

Studying consumption values will further develop an understanding of how they affect consumers purchasing decisions because "values are the implicit criteria that are employed by an individual in making a preference judgment. These criteria guide the behavior of people because they reflect the desired ultimate end states of existence" (Flint et al., 1997, p. 169). Now, I will look further into the situational factors that may play a role in consumers' purchasing decisions.

\section{2 - Consumption/Usage Situation as Conditional Value}

In my framework, I label different consumption situations with respect to their level of formality and how consumers assign different conditional value to products in such situations. Formal situations are characterized by the observation of conventional forms of ceremony. Such situations will have certain rules and guidelines to follow, such as if an individual were to go to an important business meeting, he/she would dress or even speak accordingly. Informal situations refer to everyday life or use. They are the opposite of formal situations in that individuals would not likely have specific guidelines or rules to follow, as when going to a restaurant with family members or friends.

Lai's (1991) and Belk's (1975) studies both show that consumers' purchasing decisions depend on the associations consumers make with the product and the consumption situation in which they intend to consume it because there is a clear 
relationship between the situation and the object and their combinative impact on the individual's purchasing decision. The store layout, the type of music playing in the store, the opinions of the people around a consumer, and the advertisements inside or outside of the store are likely to have an effect on consumer purchasing decisions (Kaltcheva \& Weitz, 2006). Lai (1991) states that there are three types of situations: communication, purchase, and consumption, and he also states that a consumption situation provides better purchasing behavior predictions than traditional measures of consumer attitudes. In my study, situations represent momentary encounters with those elements of the total environment, which are available to the individual at a particular time (Belk, 1975) and how these encounters influence the perceived conditional value.

Situational factors in a specific environment affect how a consumer acts in a situation. Belk (1974) defined situation as "a point in time and space outside the basic tendencies and characteristics of the individual and beyond the characteristics of the stimulus object" (p. 157). When I discuss consumption situation, I refer to the "anticipated usage situation of a product" (Lai, 1991). It is expected that the usage situation will influence a customer's preference of a product, the perceived conditional value of the product, and the likelihood of customers using the product (Srivastava, Alpert,\& Shocker, 1984). For example, an individual may use instant coffee brands when in a hurry and regular ground coffee when entertaining (Srivastava, Alpert,\& Shocker, 1984). As an another example, customers may pay more attention to the nutritional values of a snack when purchasing the products for their children, while if it is purchased for entertaining co-workers or peers, they may go with different flavors, and/or different brands where nutritional values would not be as important. In both scenarios, the 
conditional value of a product moderates the effect of other values on purchase decisions. In the first example, the first situation represents a time constraint factor in which the consumer perceives that the functional value is more important (preparing and taking the coffee); in the second situation, the consumer may feel as though he/she needs a better choice so that he/she can impress and entertain the guests better (by preparing filter coffee in the coffee machine). In the second scenario, the consumer pays more attention to nutritional attributes for her children, and in this case, the consumer could assign the product either higher functional value since it is a healthier choice, or higher emotional value since it is purchased for the well-being of her children. The same consumer may choose a snack food that is lower in nutritional values but higher in variety, which could reflect the symbolic value in terms of impressing guests or being able to entertain them well, or it could reflect the epistemic value whereby she would like to try a different snack food. In either situation, the conditional value of the chosen item will be higher and in turn, this perception of higher conditional value will be reflected in how consumers assign values.

When a consumer makes a purchase decision, although it may seem as though it is an individual decision, this choice is heavily influenced by other people (Böcker, 1986). Social factors represent the people around a consumer in a specific consumption situation, which in some contexts may include salespeople and other customers in the store (Grewal \& Baker, 1994). The presence of other people in a purchasing situation will have an impact on the decision to make a purchase (Luo, 2005). The reason is that when other consumers are around, perceived conditional value will likely moderate how the consumer assigns values, and in certain situations they may assign higher values to 
particular aspects of the product. Conditional value in these situations may moderate the effect of symbolic value wherein one may want to signal sophistication, wealth, or even frugality in certain situations. Consumers may believe that others' opinions and behaviors are credible. Luo (2005) also states, "the presence of family members may activate the normative value and therefore decrease the urge to purchase. In contrast, peer group members may encourage spontaneity and the pursuit of hedonic goals independently of their long-range consequences" (p. 289). Therefore, having different types of people around, whether they are family members or peers, may have an impact on how consumers assign values to products, which in turn affects their purchasing decisions (Luo, 2005).

The presence of other people around the consumer may have an effect on the perception and choice of the consumer in the particular consumption context. For instance, when an individual is searching for laptops, the presence of other customers may push the individual to look at moderate or high price range laptops because one would want to give the impression that the individual is capable of purchasing the higher priced item. Netemeyer et al. (1992) found that consumers who are susceptible to interpersonal influence are more likely to purchase products that will cause others to make favorable attributions about them. Therefore, the presence of other people may lead consumers to assign higher conditional value, which in turn moderates the symbolic value that they assign to a product.

Two alternative perspectives proposed for consumption contexts are labeled as “psychological" (Lutz \& Kakkar,1975) and "objective" (Belk, 1975) measurements. Psychological measurements of situations rely on the extension made to the actual, 
objective situation by consumers (Thomas, 1927). Objective measurement is the situation before the extension is made; basically, it is the plain situation unaffected by an individual's interpretations and values (Belk, 1975). The reason for separating these two perspectives is that they show the difference between a situation without additions made by the consumer and a situation where an individual is making additions to what is actually present based on his/her perspectives and values. These are also affected by the degree of involvement an individual has. Situational involvement reflects the temporary feelings of involvement that accompany a particular situation (Richins, Bloch, \& McQuarrie, 1992), and enduring involvement is an individual difference variable that a consumer brings into a situation (Richins, Bloch, \& McQuarrie, 1992). Although these two involvement types arise from different sources, they still affect how a consumer perceives a certain situation and what type of extensions they make to a situation by judging external factors through their perspectives or by evaluating the situation through internal factors that are unique to each individual (Houston \& Rothschild, 1978).

Consumers' purchasing decisions are also affected by how pleasant their shopping experiences are. Retailers' success will depend on consumers' reactions to situational elements present in the store, and in order to create a positive emotion inducing environment, retail stores can use elements such as color, layout, architecture, scents, and temperature (Grewal \& Baker, 1994). When retail stores create a future usage situation for their consumers, consumers experience the purchase in that particular situation (Rook \& Fisher, 1995). In this created environment, consumers tend to think they are either out socializing with their friends or families, which automatically affects their mood positively or negatively; in turn, it affects how they assign values to products. For 
instance, consumers may try to imagine what their friends or family may think of the decision they made, or they may try to imagine what type of message the product will likely deliver. In contrast, if a consumer is shopping for clothing and there is a nearby bakery, the smell of freshly baked bread making its way inside the retail store creates an unwanted diversion from the intended purpose of being at the retail store. This could turn a pleasant shopping experience into an unsuccessful trip and the consumer may return home empty handed. Consumers may try to visualize themselves in a future usage situation in which they can fantasize about their peers' opinions about the product. The music should be complementary to their mood, and it may be remind them of the good times they had, or funny memories from previous evenings together with their friends. Han et al. (2007) state that "incidental emotion encompasses the puzzling influence of subjective emotional experiences that should be normatively irrelevant to present judgments and choice" (p. 159). Therefore, music playing in a retail store may enhance someone's mood; in turn, the perceived conditional value of a product may increase, which may moderate the level of the perceived emotional value. Luo (2005) states that when consumers feel happy, they may be disposed to reward themselves more generously and may feel as if they have more freedom to act. Therefore, it is likely that a shopping environment will change consumers' perception of the conditional value of certain products, which in turn will impact how they assign values to products.

Situational factors will affect consumers' willingness to pay for a product. A good example is found in Thaler's (1985) study. Thaler conducted an experiment in which subjects were asked how much they would be willing to spend on a bottle of beer while they are on the beach enjoying the sun. They were told there are two purchasing 
options,one of them a rundown grocery store and the other a nearby resort hotel. The estimated prices for the two places differed greatly in that consumers' willingness to pay increased for the nearby resort hotel. This study proves that situational conditions affect the perceived value of a conditional value and how consumers' price estimates differ in such circumstances (Grewal \& Baker, 1994).

\section{3 - Purchasing Decisions}

After completing my research on purchasing decisions, it was clear that several factors affect purchasing decisions; in other words, it has an effect on consumers' willingness regarding how much to pay per unit and the quantity of the products they are willing to purchase.

Firstly, consumers make certain purchasing decisions for symbolic reasons. Symbolic purchases are done usually to signal a certain image. Consumers may engage in symbolic purchasing either to signal that they are wealthy as in the status consumption concept (Shukla, 2009), or to signal that they are sophisticated or highly educated, or even to signal that they are socially responsible individuals. Recent research insights provide evidence that consumers make decisions with the influence of external factors of which they are not usually aware (Bargh, 2002; Fitzsimons et al., 2002). For example, they may decide to look at more expensive items at a store if there are other customers around. Unconsciously this behavior is indirectly differentiating the consumer from other customers within the proximity of that person (O’Cass \& McEwen, 2004).

Consumers consider several product attributes together when making a purchasing decision. They do consider the price, the quality, and the availability of the products as well as the product attributes. Product attributes include the search attributes, experience attributes and credence attributes (De Pelsmacker et al., 2005). Search 
attributes are mainly the price, size, and color that can be judged pre-purchase (De Pelsmacker et al., 2005). Consumers decide on a product based on search attributes if they are putting more weight on these features such as when purchasing a piece of clothing which could be shirts, pants, or dresses. Even cameras would fall under search attributes because consumers tend to know the specifications they want such as its color, whether it comes with a bundle, whether it is resistant to water, and so on. On the other hand, experience features include product quality or taste, which are usually judged after the purchase (De Pelsmacker et al., 2005). For instance, wine is clearly an experience food and a typical retail wine store would have many dozens of red wines from which to choose (Mueller et al., 2010). In a situation like this, consumers will go with the packaging of the product in order to make the final decision to purchase an experience product (Mueller et al., 2010). The package becomes a critical factor if consumers do not know about the product before purchasing it, because packaging will be the key factor that communicates what the product is about at the time of purchase (Silayoi \& Speece, 2007). Credence attributes are those attributes that consumers can judge neither prepurchase nor post-purchase. Ethically labeled products fall under the credence attribute category (De Pelsmacker et al., 2005). Although they cannot judge the product before or after the purchase, consumers would still purchase ethically labeled products due to their need to express their feelings of responsibility towards society and show their appreciation for socially responsible companies (De Pelsmacker et al., 2005). Overall, product attributes will influence the purchase decisions made by consumers because being able to judge before or after the purchase will help ease their decision-making process. 
Consumers purchasing decisions are also affected by interpersonal influence (Kropp, Lavack, \& Silvera, 2005). There are major individual differences in the degree to which consumers rely on the real or perceived reactions or opinions of others with regards to attitude formation, purchasing, and consumption behavior (Kropp, Lavack, \& Silvera, 2005). Kropp et al.(2005) described the Consumer Susceptibility to Interpersonal Influence (CSII) as the measure of the degree to which a person is influenced by real or imagined others, specifically with regard to his/her consumer choices. CSII measurement includes two components: the first one is the informational and the second one is normative. The informational component is basically how much consumers are willing to learn and seek information on the product and the normative component is the individual's need to use product purchases to be identified with, and it is an individual's willingness to conform to the expectations of others in making purchasing decision (Kropp, Lavack, \& Silvera, 2005). A consumer may be influenced by other people around him/her so that he/she can fell the sense of belonging to the group and 'fit' with the group. (Kropp, Lavack, \& Silvera, 2005). However, one should note that, it does not mean that interpersonal influence only affects those who are highly susceptible. It affects everyone who considers that interpersonal influence values are important, they may care more about the other person's opinion or evaluations of themselves (Kropp, Lavack, \& Silvera, 2005).

Previous research also shows links between Country of Origin (COO) and its effects on purchasing decisions. $\mathrm{COO}$ affects purchasing decisions in a way that nationalistic consumers prefer local products. However, this is not the case anymore because there is an increasing number of immigrants around the world as well as 
consumers who are not nationalistic (Rawwas, Rajendran, \& Wuehrer, 1996). Sampson and Smith (1957) has labeled the hybrid culture and becoming increasingly appreciative of world sharing and common welfare and shows empathy and understanding towards other societies as "worldmindedness". In general, consumers use COO to simplify their purchase decisions; nationalistic consumers value COO highly as a salient attribute.

Most researchers also believe that consumers do not typically apply analytical decision rules to make optimal choices but instead rely on heuristics that lead to satisfying their goals (D’Astous, Bensouda, \& Guindon, 1989; Van Osselaer et al., 2005). Consumers adapt their decision making accordingly, which is followed by a choice based on their unique consideration set (Huneke, Cole, \& Levin, 2004). This consideration set helps them reduce the number of searches; change their search orientation, become more confident in their selection, which increases their decision efficiency (Huneke, Cole, \& Levin, 2004). Once consumers adapt a certain decision making process, the end result becomes automated. Thus, most consumers' decisions are repetitive; consequently, consumers do not go through an elaborate purchase process but may make their choices based on habit, which is called "habitual purchasing" (D'Astous, Bensouda, \& Guindon, 1989; Huneke, Cole, \& Levin, 2004).

\subsection{1 - Willingness to Pay}

Price is one of the primary determinants for the demand of a specific product (Krishnamurthi \& Raj, 1988). If consumers are trying to decide about purchasing a product, they typically consider which product to choose and how much of the product they should purchase (Krishnamurthi \& Raj, 1988). Although price is a key driver in the decision, consumers may also consider the other factors at hand when making their 
purchase decisions. A consumer may choose a specific product due to budgetary constraints, product attributes, habitual reasons, or the origin of the product.

Consumers may be willing to pay more or less if they are trying to signal their wealth or frugality. Symbolic purchases can affect their willingness to pay depending on what they want to signal. If a consumer wants to signal their sophistication, one can presume that the consumer will likely shop in stores which position themselves as sophisticated and high end.

When consumers take different product attributes into consideration, they are likely to spend more money on the product if they find an attribute that satisfies their wants or needs. For example, if a person is looking for a good camera, the individual would likely pay more money for the product that offers the best picture quality and the most durability.

Luo (2005) states that presence of family members will decrease an individual's willingness to pay for a certain product. If a consumer were to make a purchasing decision by him/herself, then he/she would likely focus more on the product and the intended usage situation. On the other hand, if family members are present, then they may encourage the individual to think about the present moment and family members might make sure that the individual needs the product and makes a good decision. In contrast, Luo (2005) states that the presence of friends increases the willingness to pay. Peer groups encourage each other to purchase items. Since purchase decisions are affected by interpersonal influence, consumers' willingness to pay will likely to be impacted by the same influential factor: interpersonal influence. 
Country of Origin (COO) can have an impact on how a consumer decides about purchasing a certain product. According to extant literature on $\mathrm{COO}$, researchers believe that nationalistic consumers are likely to prefer local products to global ones, which will likely increase their willingness to pay a premium price for the locally produced products. Due to the increasing number of immigrants all around the world, this effect is decreasing; however, it is still present (Rawwas, Rajendran, \& Wuehrer, 1996).

Consumers engage in habitual purchasing (Wood \& Neal, 2009; Baumeister, 2002) because certain context cues are activated in their memory. These cues may involve a product performing its intended purpose satisfactorily previously; therefore, consumers unconsciously assign a higher functional value to the product and repeat the purchase. Habitual purchasing might be due to symbolic value in that, if the product signaled the intended message properly and the consumers were satisfied with the message delivered, in turn, they may purchase the same product repeatedly until the message they would like to deliver changes. If a consumer makes a certain purchasing decision and the product performs its intended purpose, whether it is hedonic or utilitarian, consumers will be happy with the purchase. They may try to ease their next purchasing decision by purchasing the same product again because the item will arouse a happy, satisfactory feeling; this increases the emotional value that the product delivers. Lastly, the epistemic value of a product may lessen the urge to purchase habitually. Since the epistemic value of a product involves learning, experiencing new things, and looking for novelty; consumers may try a new product on their next purchase. If that product satisfies, they may still end up habitually purchasing, but with the new product rather than the original one.. 


\subsection{2 - Purchase Quantity}

According to Lilly (2001), when consumer decisions are related to how much of an item to purchase, whatever quantity purchased is utility maximizing for the consumer. For business-to-business customers, there are specific guidelines and certain measurements that allow them to optimize their purchases; however, an individual's decision to purchase a certain quantity of a certain item is good whatever the quantity is.

First of all, when consumers are engaged in symbolic purchasing, for whatever reasons, such as signaling sophistication, wealth, or higher education; it will likely affect their purchase quantity. By purchasing a specific amount, they may try to signal that they always use it or that this is their way of shopping. The symbolic purchases of consumers can also signal frugality. In that case, consumer may change their purchase quantity accordingly.

In addition, different product attributes will likely affect purchase quantities. The reason for this is that if an individual were to value a certain attribute in the product more than others, they will likely acquire more of the product than if they did not value the attribute as much. The attribute could be the shape of the product, its symbolic meaning, the affection the consumer holds for it, or its novelty.

Thirdly, an individual's purchase quantity will likely be affected by interpersonal influence. Luo (2005) argues that family members are likely to influence an individual's spending in a negative manner, and friends are likely to influence an individual's spending so as to encourage them to purchase more of a product.

Fourthly, COO will likely influence an individual's purchase quantity such that nationalistic consumers will likely purchase more locally based products, whereas global- 
minded consumers will likely purchase greater quantities of a global product (Steenkamp \& Jong, 2010). Although the COO effect may decreased with the increasing number of immigrants, it may still affect their purchasing decisions in terms of their willingness to pay and purchase quantity.

Lastly, purchase quantity will likely be affected by habitual purchasing. When consumers' responses are automated regarding a specific concept, they will likely engage in habitual purchasing (D'Astous, Bensouda, \& Guindon, 1989; Huneke, Cole, \& Levin, 2004; Wood \& Neal, 2009). Once the action is the result of habitual reasons, consumers will likely purchase more quantities of certain items. 


\section{CONCEPTUAL FRAMEWORK}

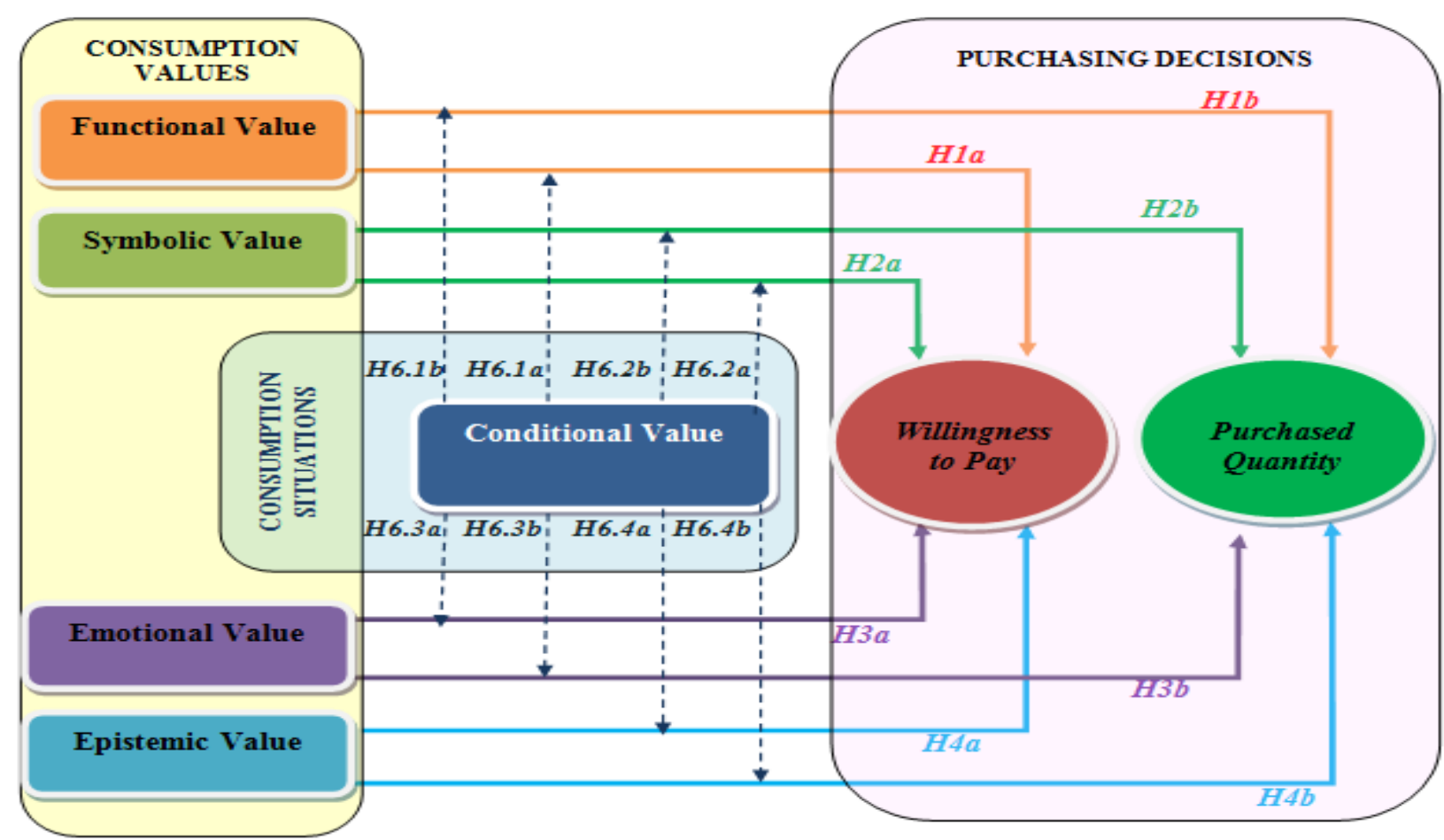

Figure 1 - Conceptual Model of the Interplay between Consumption Values and Consumption Situations on Purchasing Decisions

\section{1 - Consumption Values \& Purchasing Decisions}

People may not necessarily consume or purchase products just for habitual reasons or due to the impact other people have on them (Wood \& Neal, 2009). Consumers' purchase decisions might reflect a continued preference for a particular product, a belief that it meets valued goals, or that it triggers the experience of positive emotions (Wood \& Neal, 2009). In this section, I will go into more detail on how consumers' value structures may affect their purchasing decisions.

The amount of weight given to each property of a product might differ according to consumers' end goals because one consumer may value the tangible characteristics such as the color of the product, the texture of the product, and so on, whereas another consumer might value the image properties of the same product more (Lefkoff-Hagius \& 
Mason, 1993). Sheth, Newman and Gross (1991) have stated that functional values are the perceived utility of a product. Consumers may be looking purely for the functional value from the product such as performing well and/or providing the maximum benefit for the price; in short, consumers may look at the attitudinal variables (Ferber, 1973). In Hoon Ang's study (2000), three categories of product attributes have been identified as having differentiating effects on preference judgment and hence purchase intention. Physical properties refer to tangible characteristics. Beneficial properties pertain to those that are intangible and offer benefit. Image properties refer to the augmented product that provides a psychological benefit to consumers. Although these are the actual properties of a certain product, consumers do not always see the products same way. One may have different perceived values of the product being considered, depending on their expectations of how the product should perform. Zeithaml (1988) states that the perceived quality of a certain alternative does not mean that it is the actual, objective quality of the alternative. When a consumer is making a purchasing decision, one inferior quality item might be good enough to deliver the wanted functional value of the product. Several scholars have argued that the information processing perspective was too narrow since it only included the utilitarian criteria, hence basically judging the products on how well they performed their proper function (Sweeney \& Soutar, 2001). Similarly, Hirschman and Holbrook (1982) have argued that experiential perspectives were broader compared to the information processing perspective and that experiential perspectives are based on appreciating the products for their own sake or for their symbolic, hedonic, and esthetic aspects. 
Hoon Ang's (2000) image properties fall under the category in which a consumer will likely purchase a product with regards to its image properties, which are a dimension of the symbolic value (Sheth et al., 1991) that they assign the product. An individual will likely purchase a product if it is helping them reach their desired psychological goal. Since symbolic values demonstrate consumers' perceptions of an item and how well it fits with special reference groups (White \& Dahl, 2006), signal status (Shukla, 2009), or send a message (Park, Jaworski, \& MacInnis, 1986), when consumers assign higher symbolic value to a product, this will likely increase their willingness to pay and their purchase quantity of the product.

Emotional values refer to "the perceived utility acquired from an alternative's capacity to arouse feelings or affective states" (Sheth, Newman, \& Gross, 1991, p. 161) and MacKay (1999) states that "emotions play a part in every purchase decision" (p. 182). When consumers are shopping for an item about which they do not have enough knowledge or experience, either they will try to make a decision through the intrinsic cues a product possesses, such as taste or texture, or they may make a decision based on extrinsic cues such as brand name or packaging. For example, the color of the packaging may trigger certain affective states in consumers. Therefore, some products arouse certain feelings and emotions which will help consumers shape their emotional values with regards to the product. Although emotional value is usually linked to aesthetic alternatives, more tangible and seemingly utilitarian products may also have emotional value as in the case of seeing a product that reminds an individual of childhood memories (Kotler, 1974; Sheth, Newman, \& Gross, 1991). If a consumer walks into a store and sees a chocolate bar which reminds them of childhood memories, then he/she might purchase 
the product. Similarly, if an individual were to purchase a product for the first time and if the product satisfies their needs or wants, the consumer will likely purchase the product on their next visit to the store, which in turn will likely increase their willingness to pay and increase their purchase quantity.

The epistemic value of a product refers to "the perceived utility acquired from an alternative's capacity to arouse curiosity, provide novelty, and/or satisfy a desire for knowledge" (Sheth, Newman, \& Gross, 1991, p. 162). When consumers are bored with their existing choice of product, they may want to explore new tastes and/or new experiences (Hirschman, 1980). Choosing an option that satisfies a consumer's need for creativity and choosing something different is basically the epistemic value of the product (Sheth, Newman, \& Gross, 1991). Epistemic value is directly linked with how much a consumer is willing to learn and experience, which is a part of the psychological influence. If consumers are likely to experiment with new products and/or experience novel products, they will likely assign higher epistemic values to new or novel products. Thus, this will likely increase their willingness to pay for a new item.

Sweeney and Soutar (2001) describe conditional value as "being derived from temporary functional or symbolic value; hence it arises when situational factors moderate the perceived value-outcome process" (p. 208). Conditional value is basically when a consumer needs to make a decision in a certain situation, such as deciding under time pressure or based on financial constraints (Howard \& Sheth, 1969; Sheth, Newman, \& Gross, 1991). For instance, the value that consumers associate with a product might be specific to a use situation and a trade-off between benefits and costs or sacrifices (Overby, Gardial, \& Woodruff, 2004). The consumer may choose a different type of wine 
depending on if he/she is dining with friends, co-workers, or family. The reason is that consumers may want to signal different messages to the different sets of groups they are with when they are making the decision. When having friends around, a consumer would likely choose whatever he/she is comfortable drinking or purchasing but with co-workers, he/she may prefer a higher priced wine as a signal of wealth and status. Also, consumers will likely look for the product that delivers the maximum conditional value such as purchasing birthday cards or purchasing gifts for different occasions, or buying suits for business meetings.

Sheth, Newman, and Gross (1991) argued that the consumption values affect a consumer's decisions separately. In contrast, Sweeney and Soutar (2001) argued that the values are related. Since both groups of scholars' views are correct, in my study, I will evaluate their effect on purchasing decisions separately and will also check for relationships between them.

\section{2 - Consumption Situation \& Purchasing Decisions}

Individuals tend to make different decisions or adopt different decision-making processes when they are alone as opposed to when they are with other people. In addition, decisions differ in different usage situations. Consumers will have different choices when they are with family members, co-workers, friends, other customers, or even when salespeople are present in the store (Luo, 2005). Consumers may choose to purchase one product over another, or they may choose to buy or not buy a product in a specific consumption situation.

Scholars agree that consumption situation affects consumers' purchasing decisions. Lai (1991) developed the Situation-Product-Consumer-Intention (SPCI) model based on the familiar stimulus-organism-response paradigm, dividing the stimulus into 
"incoming information of new product" and "perceived situation needs" (p.57). The consumer reacts to these two stimuli and makes a purchase decision regarding the product (Lai, 1991). Referring to the SPCI model, it seems that a clear distinction may be made among consumers, product, and situation as separate sources of influence on behavior, although some potential confusion may exist (Lai, 1991). Lai (1991) suggests that the individuality of consumers is key when differentiating the personal and contextual factors. The potential confusion may be the result of thinking that consumer values and the consumption situation will affect purchasing decisions when consumers are in certain consumption situations. Thus, for consumer values and usage situation with one product, one consumer may perceive only one linkage between a specific attribute, consequence, and end state, while another consumer may perceive multiple linkages between several attributes, consequences, and end-states (Overby, Gardial, \& Woodruff, 2004).

Prior studies argue that consumers tend to decide on a specific alternative when they are at the store rather than engaging in extensive pre-planning (Bettman \& Zins, 1977; Biehal \& Chakravarti, 1986). When consumers try to evaluate a product in order to purchase it, they will try to choose the one that will satisfy underlying consumption values such as utilitarian or hedonic purchases (Corfman, Lehman, \& Narayanan, 1991). According to Overby, Gardial, and Woodruff (2004), consequences describe what a consumer experiences when using a product or service in a consumption context. There are three different types of consequences. Functional consequences represent the ability of a product or service to perform its utilitarian purposes. Consumers estimate a product's utility by adjusting for price, and they rank the options according to their buying 
priorities (Corfman, Lehman, \& Narayanan, 1991). Personal consequences represent the ability of a product or service to satisfy important intrinsic goals that are self-oriented and/or symbolic. Social consequences represent the ability of a product or service to portray an image to others that is congruent with the norms of significant others. Their values play an important role with regards to social consequences because Schwartz (1994) defines human values as "desirable trans-situational goals, varying in importance, that serve as guiding principles in the life of a person or other social entity" (p.21).

According to Baumeister (2002), if consumers do not know what they want, they are more prone to external influences because consumers tend to use external factors such as sales personnel, advertisers, in-store stimuli, family members, and friends as sources of their purchasing behavior (Baumeister, 2002).Consumers try to decrease the perceived risk, believe in the opinions of others who share similar values, or fit in with society or their peer group (Bearden \& Etzel, 1982). Consumers tend to verbally communicate with their peers in order to evaluate their judgments in purchase situations, thus deciding based on what their peers evaluate as appropriate (Bearden \& Etzel, 1982). Some consumers use in-store stimuli as cues to remind them of what groceries they need. Other consumers enter the store with an intention to buy only a certain set of goods, but this quickly changes as the in-store stimuli lead to purchases of unintended items. In either case, instore stimuli trigger unrecognized needs and desires or trigger memories for forgotten needs, leading to in-store decision making or unplanned purchasing (Inman, Winder, \& Ferraro, 2009). Brand antecedents are management- and marketing-controlled brand features that express an intended message to consumers (Shukla, 2009). Situational antecedents are the consumption or usage context that the consumers are in. This means 
that consumers make different purchase decisions in different usage situations. When they are with family, they may prefer a different alternative than when they are with coworkers or friends.

Habitual purchasing is another end result of situational effects on consumer purchasing decisions. Environments automatically activate goals in consumers' minds and they guide the information processing, which in turn affects the purchasing decision made without conscious intervention (Bargh, 2002; Fitzsimons et al., 2002), because consumers form habits when they repeatedly respond in stable contexts (Wood \& Neal, 2009). The reason is that strong attitudes are highly accessible from memory and can be retrieved quickly; this leads to an automatic activation of the goal, thus changing or not changing the choices made regardless of the initial intention (Fitzsimons et al., 2002). Reaction time studies indicate that specific context cues will activate habitual responses in the memory (Wood \& Neal, 2009). When people perform a specific action in a particular context, the context can trigger an automatic response, which would not require supporting goals or intentions (Wood \& Neal, 2007; Neal, Wood, \& Quinn, 2006; Wood $\&$ Neal, 2009). For instance, consumers at a movie theatre were tested to uncover the automatic responses they had while watching a movie. They were given stale and fresh sets of popcorn before entering the movie theatre and while watching the movie. The results showed that the context cue of being in a movie theatre activated the habitual response of eating popcorn while watching movie and, as a result, all respondents finished the stale popcorn although they reportedly found it very unappetizing (Wood \& Neal, 2009). 


\section{HYPOTHESES \\ 4.1 - The Effect of Consumer Values on Purchasing Decisions \\ 4.1.1 -Functional Value}

Sheth et al. (1991) argue that functional value is created by the perceived quality of the products, which could come in the form of reliability, durability, flexibility, lifetime value of a product, shelf-time of a product, performance attributes of a product, comparability, characteristics, and usability. Consumers need to be able to perceive the higher functional benefit of a product when they are making a purchase decision. They need to be able to see that the product will provide them with the functional value they want and the functional benefit they need. The purchase decision could be based on how often they will use the product or how long they would like to keep it for. Consumers may expect to receive the same performance from the product every time the product is used.

A product with higher perceived quality will have a higher functional value, which will increase consumers' willingness to pay. Higher quality products can mean different things to different consumers. As such, I use the term 'perceived higher quality' because perceived higher quality could be in the form of more durability, more reliability, having a longer shelf life, and/or offering more features for consumers. Strausz's (2009) study shows that consumers are only willing to pay $50 \%$ of the price when companies slash the lifetime value of a product in half; however, consumers would not hesitate to pay the asking price or even more when the functional value of a product is higher due to the higher perceived quality of the product.

One way that consumers judge the functional value of a product is from Country of Origin cues. These geographical indications are used as a means of certifying that the 
products are known for the quality, reputation, and characteristics of goods produced in particular areas (Park \& Yanos, 2006). Therefore, the geographical indication of a product is also a physical attribute; it shows where the product was made, thus leading a consumer to choose a certain alternative over another because the place it was made is a factor in its value. This is true for most experience products, particularly when consumers have no prior exposure to them (Mueller et al., 2010). Examples of such geographical indications are Champagne, which is the name of a wine production region in the far north of France; Scotch whisky or Scotch, whisky which is produced in Scotland; and a dry-cured ham from the Parma region in Italy called Parma ham (Park \& Yanos, 2006). For instance, if a consumer were to purchase a bottle of wine, about which he/she has little information, he/she may base his/her decision on the aspect of where it was made because it offers an idea of the taste and quality of the wine. Benfratello, Piacenza, and Sacchetto (2009) stated that a higher perceived functional value of a product increases consumer willingness to pay when there is imperfect information. In deciding which wine to purchase, looking at its year, how long it can be kept for, how high the acidity level is, and all other physical aspects, will help consumers assign a level of functional value to the product. Basically, consumers use country of origin cue attributes as a proxy for judging the overall functional value of the product by looking at indicators of existing product attributes such as safety, nutrition, freshness, taste, and so on (Gao, Schroeder, \& $\mathrm{Yu}, 2010)$.

The physical properties of products help consumers see the functionality benefits a product offers (Hoon Ang, 2000). Consumers will likely assign higher functional value to a product if they perceive the product will allow them to reach their desired end goal 
such as having a higher nutritional value or having a higher standard for healthy living (Lefkoff-Hagius \& Mason, 1993; Umberger, Boxall, \& Lacy, 2009). For instance, if the product offers better indoor air quality and lighting that provides a healthy home concept or the product offers more add-on features so that consumers can use a product's utility to update their preferences or the information they have on the product, this will increase the functional value of the product (Spetic, Kozak, \& Cohen, 2004; Bertini, Ofek, \& Ariely, 2009). In short, the desired physical properties of a product will increase its functionality; thus, consumers will assign higher functional value to the product, which in turn will increase their willingness to pay for the item.

The compatibility of a product will likely increase its functional value. Consumers who seek a product that they can use for different applications will be willing to pay more for the product because its perceived functionality will be higher. For instance, wine can be consumed leisurely with cheese and crackers, or it could be a complementary drink for meals. A consumer may purchase the drink either to entertain guests and drink leisurely, or they may choose to purchase this product for other benefits such as reducing the risk of cardiovascular disease, diabetes, and blood cholesterol levels (Leskosek-Cukalovic et al., 2010). This is also true for durable products such as the brand 'Bounce.' It was created to be used as dryer sheets, and then newer uses were found for it such as hanging it in the closet to refresh clothes, or placing it in shoes to refresh or eliminate odors.

When a product's perceived functional value is well embedded within its functional features, consumers will perceive the product as having a higher value than its counterparts; and when consumers perceive a higher functional value, their willingness to 
pay will be higher as well (Lopes \& Galletta, 2006; Dodds, Monroe, \& Grewal, 1991). Therefore, I formulate the following hypothesis:

Hla: Perceived functional value is positively associated with consumers' willingness to pay.

When consumers perceive a higher functionality in a product, they will likely purchase more of that item. The functionality of a product could be in the form of the attributes it offers, its perceived quality, and/or its usability. Once consumers make the purchase and the product delivers the perceived functional value, they will likely purchase the same item on their next shopping trip. Consumers may engage in habitual purchasing because they know that product will deliver the same performance every time (D’Astous, Bensouda, \& Guindon, 1989; Huneke, Cole, \& Levin, 2004). By engaging in habitual purchasing, consumers will show that they perceive a higher functional value in a product, which will have an effect on their purchase quantity.

Consumers' choices of products are largely driven by the different features of the products offered. Buyers with a strong taste for a given feature of a product are more likely to acquire more of the product (Bonatti, 2011) because they perceive that the products have higher functional benefit, functional value, and/or functional features. For instance, if a specific bottle of wine can be cellared for a long time, consumers may purchase more of that item so they can store the wine because they know that it has a longer shelf time compared to other alternatives. Another individual may purchase more of the same bottle of wine because he/she may enjoy the taste. All these different features a product offers will increase the perceived functionality and increased functional value, and will increase the purchase quantity of the product. 
A product's perceived quality will increase its functional value and as a result, consumers will purchase more of the item (Strausz, 2009). Perceived quality could mean that the product has a longer shelf life so consumers can purchase more of the item and store it. Perceived quality may also refer to how a product was made, what type of materials or parts were used, and/or how many different features it may offer (Lopes \& Galletta, 2006). Once a consumer finds a product that meets one or more of the above requirements, they will likely purchase more of the product because they know that the product will perform its intended action satisfactorily.

The usability of a product will show the level of functional value a product has to offer the consumer. A consumer may look for a product that is easy to use and navigate. For instance, consumers may purchase a pitcher that does not tire the hand or does not spill when they are trying to pour something into a cup. They may purchase more pitchers for themselves or for other people because they know that the pitcher is easy to use.

In addition, Ainslie and Rossi's (1998) study has shown that consumers with sharply defined preferences for certain products have higher purchase quantities. The place that a product is made is a sign of quality in terms of reliability or reputation for consumers because country of origin cues can positively influence demand for the product, as might be the case with an exotic vacation (Park \& Yanos, 2006; Schupp, Gilespie, O’Neil, Prinyawiwatkul, \& Makienko, 2005).

Therefore, I formulate the following hypothesis:

H1b: Perceived functional value is positively associated with the quantity purchased. 


\subsection{2 - Symbolic Value}

Individual behavior is often motivated by self-presentation or impression management (Ashworth \& Matear, 2009). Consumers assign symbolic value to products because products can serve as signaling devices to members of the opposite sex, they can represent their owners' self-concepts to others, they can identify owners with valued reference groups, and they can symbolize accomplishments (Heaney, Goldsmith, \& Jusoh, 2005; Sheth, Newman, \& Gross, 1991; Narayan, Rao, \& Saunders, 2011).

The product of focus may be liked or disliked by others, which will likely shape how a consumer assigns symbolic value to the product at the time of purchase. A consumer may perceive a higher symbolic value in a product if the product is used by a celebrity or a role model, so that he/she feels that he/she is associated with his/her role model (Heaney, Goldsmith, \& Jusoh, 2005), and because people conform in order to be accepted by others or not to stand out or be perceived as odd (Grapentine \& Weaver, 2009). When the product helps consumers be validated by others or a specific group and signals appreciation of a celebrity by dressing like her/him, consumers will assign higher symbolic value, and increased symbolic value will increase their willingness to pay.

When a product delivers the intended message satisfactorily, the consumer will assign a higher symbolic value to the product, which will be reflected as an increased willingness to pay for the item. This message could be sophistication, wealth, higher education, socially responsible behavior, or frugality. When a product helps consumers achieve or avoid certain impressions and help them signal their unobservable income, consumers will perceive a higher symbolic value in the product (Ashworth \& Matear's, 2009; Moav \& Neeman, 2010). Consumers are also willing to pay a higher price for 
products that satisfy certain symbolic environmental objectives (Basu \& Hicks, 2008) because then their purchase will signal to others that the consumer is caring for the environment. This could be in the form of making purchases to protect other species (Naald \& Cameron, 2011) or purchasing from a company that is engaged in socially responsible activities. When these intended messages are more distinct in an alternative, the perceived symbolic value will be higher, thus, willingness to pay for the product will also be higher.

Status consumption is "the motivational processes by which individuals strive to improve their social standing through the conspicuous consumption of consumer products that confer and symbolize status both for the individual and surrounding significant others" (Eastman et al., 1999, p. 42).Sophisticated, educated consumers who are from a certain background see products as tools for social networking and drivers of status rather than seeing them in terms of wants or needs (Loulakis \& Hill, 2010). Rucker and Galinsky (2008) also proved that less powerful consumers' willingness to pay for products that are considered to have high symbolic value will likely be high because they would like to gain control or power by using the products, and thereby signal a certain message, such as status or power. Therefore, I formulate the following hypothesis:

H2a: Perceived symbolic value is positively associated with consumers' willingness to pay.

If a consumer is satisfied with the result of their purchase, in other words, the purchased product has signaled the intended message to the consumer's peers, friends, or co-workers, it is likely that the consumer will not change their subsequent purchasing decisions because the signaled message needs to be consistent. In order to signal a 
message, impress other individuals, or symbolize accomplishments (Moav \& Neeman, 2010), consumers will likely purchase higher quantities of the product.

Status consumption usually refers to the norms that are expected of the consumer at the time of purchase (Liebenstein, 1950). When a product satisfactorily signals the status of an individual, the perceived symbolic value will be higher; therefore, the consumer will likely purchase higher quantities of the product. For instance, the middleclass population engages in status consumption in order to maintain and reinforce their class position (Banks, 2010). Therefore, by engaging in status consumption, consumers will likely perceive higher symbolic value, which in turn will increase their purchase quantity.

If a consumer purchased a product in order to impress his/her peers and signal that he/she has the financial ability to purchase an expensive item, or if an individual is caring for the environment by purchasing products that protect other species or are organically produced (Naald \& Cameron, 2011; Graham \& Bansal, 2007), then the consumer will likely purchase the same item next time in order to keep the message consistent. A consumer may purchase more products that signal environmental responsibility so that he/she can signal that he/she cares for the environment and other species (Naald \& Cameron, 2011; Basu \& Hicks, 2008). Similarly, consumers may signal that they care for their local businesses by purchasing locally produced products (Rawwas, Rajendran, \& Wuehrer, 1996), or that they have a healthier lifestyle by purchasing and consuming organic food (Basu \& Hicks, 2008). When consumers try to signal a certain message, they need to purchase the products regularly so that their consumption pattern is clear to others and the message delivered is consistent. 
Certain kinds of retailers send messages about their consumers through their image because the store's perceived image provides information (Champion, Hunt, \&Hunt, 2010) that allows consumers to assign a level of symbolic value to its products. If an individual shops from a discount store, he/she may want to show others that he/she is frugal. Of course, this can happen in a status consumption scenario in which a consumer may shop from a high-end store and purchase more products at once in order to signal that he/she 'can'. Reputational factors such as being fashionable, offering advanced products, or being socially responsible (Graham \& Bansal, 2007) increases the symbolic value of a product because these factors help consumers signal a certain message to others. In order to keep the message consistent, a consumer will likely purchase more of the product, and more frequently. Therefore, I formulate the following hypothesis:

H2b: Perceived symbolic value is positively associated with the quantity purchased.

\subsection{3 - Emotional Value}

Barlow and Maul (2010) note the following:

emotion is central to our lives as humans, which include not only our families and friends and those close to us but also the many people we interact with ... the role of emotion is becoming increasingly recognized as a critical aspect of these interactions and indeed very often comprises the core of the value we receive (p. vii).

Sheth, Newman, and Gross (1991) define emotional value as an alternative's capacity to arouse feelings or affective states, and Barlow and Maul (2010) define emotional value as "the economic worth of feelings." A consumer would assign a higher 
emotional value to a product if the consumer receives positive and/or memorable experiences from the product.

When consumers receive a positive emotional benefit from a product, which could be either satisfaction or happiness, they tend to assign a higher emotional value to the product. In fact, positive emotions usually have the ability to down-regulate the effects of negativity (Kemp \& Kopp, 2011).Although positive emotions tend to downregulate or reduce the effect of negative emotions, when consumers have negative feelings associated with the product, such as regret, these negative feelings are still reflected in their purchasing decisions (Tsiros \& Mittal, 2000) and, more specifically, in their willingness to pay. Bui et al.(2009) also added that regret, being a powerful emotion, may affect a consumers' purchasing decision in a way that they will make a comparison between two options based on their prior experiences with the product. When this occurs, a consumer will be willing to pay more for a product that is higher in emotional value than the "regret" they feel when they reflect on the purchase. Therefore, when a product arouses a certain feeling, it will affect the perceived emotional value and in turn, it will affect a consumer's willingness to pay.

Individuals make certain decisions by relying on their prior experiences, which could include ordinary memories or more meaningful experiences (Zauberman, Ratner, \& Kim, 2008). An ordinary memory could be a chocolate bar that a consumer had when he/she was a kid or even a satisfactory memory of the product. When consumers engage in nostalgic thinking, they tend to think about the meaningful memories that increase an individual's self-regard and positive affect (Zauberman, Ratner, \& Kim, 2008). The personal nostalgia experience comprises both cognitive and affective dimensions. 
Previous research shows that personal nostalgia evokes a variety of emotions (Ford \& Merchant, 2010) and those consumers tend to spend more on products that make them nostalgic. For instance, consumers often like to keep their memories of family or friends in a nice photo album; thus, they usually assign a higher emotional value to the photograph album, which in turn increases their willingness to pay for it. Therefore, I formulate the following hypothesis:

H3a: Perceived emotional value is positively associated with consumers' willingness to pay.

Most consumers know how they are emotionally impacted from the moment they see or consider purchasing or not purchasing a product (Barlow \& Maul, 2010). Consumers may purchase higher quantities or may purchase a product more often when the product arouses a feeling. For instance, a consumer may feel very entertained after watching a movie at a movie theater and may go back to watch more movies at the same theatre. Another consumer may really enjoy a specific bottle of wine because it reminds them of their parents' choice of wine.

According to research done by Atalay and Meloy (2011), when people are feeling negative, they tend to cheer themselves up by shopping, and they usually have no idea that this is the true intention of the shopping trip. On the other hand, when consumers feel positive, they tend to assign higher emotional value to a product because they may think that the product is the source of positivity, happiness, and the good mood they are in; thus, being in a good mood also increases their purchase quantity. In addition to the positive mood of consumers, Saad's (2006) study showed that when consumers are in a celebratory mood, their average spending increases. When consumers are in a good, 
cheerful mood, this positive effect is reflected in their purchasing decisions (Saad, 2006) as an increase in the quantity because they tend to perceive a higher emotional value in the product.

A hedonic tone of consumption may trigger pleasant memories, which could lead consumers to build positive attitudes toward a product (Posavac, Herzstein, \& Sanbonmatsu, 2003; Dube, Cecile-Cervellon, \& Jingyuan, 2003), and subsequently increase the perceived emotional value of the product. When consumers have prior experience with the product, the emotional value becomes a stronger influence because it arouses certain feelings and evokes nostalgia. Ford and Merchant (2010) states that nostalgia evokes a variety of emotions and consumers tend to purchase more because nostalgia increases the perceived emotional value.

When a product arouses a certain affective state in a consumer, the perceived emotional value of the product will likely increase, which affects consumers' purchasing quantity. Thus, I formulate the following hypothesis:

H3b: Perceived emotional value will be positively related to the quantity purchased.

\subsection{4 - Epistemic Value}

Epistemic values is a product's capacity to arouse curiosity, offer novelty, or satisfy a desire for knowledge and may be important to consumers who are considering new experiences (Sheth, Newman, \& Gross, 1991). When consumers are willing to try new products or are willing to change their current choice of product, they will be more inclined to purchase new products. The newness of the product depends on how novel a consumer perceives the product to be because consumers need to perceive the product as 
different and interesting (Blake et al., 1973). Novel features of a product can be experienced only through use (Meyer, Zhao, \& Han, 2008), and when consumers seek novelty in products, they will perceive a higher epistemic value and pay a higher price in order to acquire or experience the product (Blake et al., 1973). For instance, if a consumer is thinking to change his/her cell phone, he/she will likely to pay more for another one that is a newer model or has recently been launched because it offers novelty (Meyer et al., 2008) and increases the epistemic value of the product.

When consumers see a different or interesting product, they may be inclined to try it out. Once they are inclined to look for a different product, they will assign higher epistemic value to the product, to the extent of the difference they perceive compared to the alternatives. In general, consumers delay their decisions for different or interesting products (Wang \& Xie, 2011); however, once an interesting product starts to show up on shelves in every store, consumers' curiosity levels increase, which increases the perceived epistemic value of the product. Once consumers assign a higher epistemic value to a product, their willingness to pay for the product will also increase.

The value of information as a contributory factor to consumers' acceptance cannot be underestimated (Depositario, Nayga, Wu, \& Laude, 2009). If consumers perceive that the product will increase their knowledge or inform them in a way that they want, then the perceived epistemic value of the product will be higher. For instance, students who enroll in universities or colleges weigh the epistemic value of education higher; therefore, they are willing to pay more for schooling, learning, and experiencing new things. If they did not think that the university or a college would give them what 
they expected, then the willingness to pay would decrease and they would drop out of school.

When consumers are engaged in these types of purchasing decisions, the epistemic value will be the primary driver due to the need for novel and interesting products; this in turn will increase consumers' willingness to pay for the product. Therefore, I formulate the following hypothesis:

H4a: Perceived epistemic value is positively associated with consumers' willingness to pay.

The newness of a product will likely increase consumers' purchase quantity because the perceived newness of the product seems to offer something different or interesting to consumers. In short, the perceived newness needs to offer novelty to consumers (Meyer et al.,2008). The novelty a product offers will be the reason for consumers to perceive it as something new (Blake et al., 1973), which will increase the perceived epistemic value of the product. For instance, a certain tissue company offers tissues with lotion and they also offer dinner napkins that consumers can use to complete their dinner table. These new products offer novelty because the products have not changed dramatically but just added a different feature (the lotion) or in the second case, the product offers options for consumers and allows them to experience a different feature of the product. Consumers will likely assign higher epistemic value to the products and try them, which will increase their purchase quantity of the item.

Consumers change their purchasing decisions when they want to experience different products. Previous experiences with prior decisions create the base for their current decisions (Inman \& Zeelengberg, 2002), and consumers will assign a higher 
epistemic value to a product that provides the necessary novelty. This novelty could involve picking a different bottle of wine rather than the one they always drink, or it could even mean going to another restaurant rather than one they always patronize. Therefore, when consumers seek out a different or interesting product, the perceived epistemic value of the product increases, which then increases their purchase quantity.

The perceived epistemic value of a product will likely change when the information changes (Depositario et al., 2009). For instance, if a student who is enrolled in a college or university program feels that there is actually a benefit to their enrollment, he/she will likely stay in school and continue his/her education. On the other hand, if the same student did not perceive any benefit from the program, he/she may change majors or drop out of school. In the latter case, the alternate major the student plans to switch to has a higher epistemic value than the student's current choice. If another consumer has found a new hobby that arouses curiosity, then the consumer will likely start purchasing items in order to get involved in her or his new hobby.

If products satisfy the need for novelty, uniqueness, and information, then the perceived epistemic value of the product increases; this will increase a consumer's purchase quantity. Thus, I propose the following hypothesis:

H4b: Perceived epistemic value is positively associated with the quantity purchased.

\subsection{5 - Conditional Value}

It is expected that the usage situation will influence customers' preference for a product and the likelihood of customers using the product (Srivastava, Alpert, \& Shocker, 1984). Consumers in certain usage situations will likely assign a higher conditional value 
to products. The conditional value of a product refers to situation-specific purchase decisions as in the case of purchasing seasonal greeting cards, in emergency situations such as when ambulance service is needed, or simply purchasing popcorn at a movie theatre (Sheth, Newman, \& Gross, 1991); thus, situations that are at a specific point in time will likely bring into play certain context cues when consumers are in different types of situations (Wood \& Neal, 2009). For instance, formal situations are types of situations in which individuals are expected to act in a certain manner (Liebenstein, 1950). Formal situations usually involve certain structure, rules, and guidelines; they require an individual to use proper communication skills; they may be more impersonal; and there tends to be levels of discipline present (Morand, 1995). Having dinner with a significant other, being in a business meeting whether it is at a meeting room or at a restaurant, or attending an organized function are all examples of formal situations. In certain situations, the level of formality may be lower than at other times; however, in every case, some degree of rules, guidelines, and structure is present. Consumers would be assigning higher conditional values to products, which in turn will likely affect their willingness to spend more for a chosen alternative in order to impress others (Ashworth \& Matear, 2009), send a message, or signal status (Shukla, 2009; Power \& Mont, 2010; Eastman \& Eastman, 2011; Thompson \& Norton, 2011) in formal contexts.

Chow, Celsi,and Abel (1990) pointed out that the presence of significant others or the perceived importance of an event has an effect on consumers' choices in a particular context. For instance, a consumer may purchase a classy, full-bodied Claret for a formal dinner party or may purchase a less expensive wine for a picnic (Quester \& Smart, 1998). The reason for the difference between these two choices is that consumers' decisions 
change according to the situation and how much conditional value they assign to a product. Consumers may make purchasing decisions that are appropriate for the situation in order to impress others around them. Goodwin (1992) defines appropriateness as "suitability, goodness of fit, congruence, lack of artifice and wise choice" (p. 739). In general, appropriateness is "knowing-how-to-act" (Goodwin, 1992). In formal situations, there are certain rules and guidelines that an individual may need to follow. For a business meeting, an individual may need to dress in business attire; for a dinner with a significant other, an individual may need to dress more formally than usual. In order to impress the other party or parties, an individual will likely spend more on products than regular times because the conditional value they will assign to the product will likely be higher. An increased willingness to pay could take the form of a more expensive business suit, or it could influence what customers' order at a restaurant, such as ordering a glass of high-end wine, or ordering a bottle of wine in contrast to the glass of wine that they would usually order. In either of formal situations mentioned above, a consumer will likely assign a higher conditional value to a product which in turn will increase their willingness to pay.

Consumers may use their purchase decisions to mark their status. Nunes (2009) defined status as "one's ranking in the vertical stratification of social groups" (p.12). When considering a formal situation such as a business dinner, a higher-level manager may order a more sophisticated wine compared to his/her subordinates or order a bottle of wine in order to signal that he/she is one of those consumers who have the means and the knowledge to do so. In addition, an executive may purchase a designer suit to help define his status at a new workplace (Das et al.,2010). All these examples indicate that 
consumers in formal settings will likely assign a higher conditional value to a product and spend more on certain items that will signal their status so that the item will set them apart from their peers and/or help them 'fit in' with others in the same context (Power \& Mont, 2010).

Consumers are likely to make purchase decisions in formal settings in order to signal a message to others around them regarding their wealth or their place in the society (Nunes, 2009). Das et al.(2010) suggest that a man wearing a different and more expensive type of sweater may appear more powerful and affluent than a man wearing an ordinary sweater that everyone wears. In a formal situation context, a consumer may choose to purchase a product that signals a message and has a higher conditional value, thereby demonstrating that the person is from a higher status background, or that he/she is a professional. The person's willingness to pay for an item that will deliver this message best will increase. Therefore, I propose the following hypothesis:

H5a: Conditional value (related to formalization of situation) is positively associated with consumers' willingness to pay.

When there are rules and guidelines that are more obvious in a specific context, the formality of the situation will be higher. In formal situations, a consumer's purchase quantity will likely increase because when consumers try to impress others, they need to keep their image consistent. For instance, during a business dinner, an individual may order a glass of wine in order to make others form an impression about them which could involve acting appropriately (Goodwin, 1992), being professional (Power \& Mont, 2010), or having high standards (Thompson \& Norton, 2011). In order to reflect a clear and consistent image, the individual will need to purchase the same item or order the same 
glass of wine more than he/she usually would when he/she is alone. By repeating the pattern, a consumer will prove that the conditional value assigned to a product is significantly high. When individuals are in a formal situation, they will likely to try to impress others, which in turn, will reflect how much conditional value they assign to specific items. This will increase their purchase quantity because they need to be consistent in their actions.

In formal situations, individuals will be more likely to use language that is more formal and that suits the context because such formality of language will represent their knowledge and appropriateness for the situation. Their language will signal that they are well mannered or know what to do and how to do it (Goodwin, 1992). When individuals want to signal a certain message, they want others to receive the message accurately; therefore, their consumption patterns should be in line with what they are trying to say. The proper use of communication skills will determine the level of formality of a situation and the level of formality will likely determine whether a product is perceived as having a high conditional value. For instance, at a business dinner, the language used would be more formal and may involve using specific business terminology or using proper honorifics (Morand, 1995), which increase the level of formality. In this context, a consumer may order a glass of wine that is high-end, which shows that the conditional value assigned to the chosen alternative is high. The product purchased could be used as a signal to show that the consumer is professional or knowledgeable. In an informal setting, consumers may still pay attention to how they speak but there would be more room to make errors or less attention paid to the proper enunciation of words, which decreases the level of formality. When consumers are in a formal situation, they would like to signal a 
certain message by making different purchasing decisions and assigning higher conditional value to products. In order to keep the message consistent, they are likely to purchase more of an item so that the people around them receive the intended message accurately. Therefore, a formal situation will likely increase the purchase quantity.

In a formal situation, a consumer may want to mark their status by purchasing certain types of products. Thompson and Norton (2011) state that there are three different purchase patterns that consumers engage in when they are trying to mark their status. The first one is the in-between category in which consumers purchase items that others do not have access to, such as owning a private jet as the boss of the organization or purchasing more expensive bottles of wine for company parties. The second category they identified is the within category in which consumers purchase an item from the same product category but at a different price range, such as purchasing a more expensive business suit than one's subordinates. Lastly, the third category is the within-product category in which consumers purchase the same product with more features, such as ordering a glass of wine that is more reputable. These examples for three different categories show that consumers are likely to assign a higher conditional value to certain items in specific situations. When consumers are in a formal situation where they are with co-workers or with people that they have just met, they may want to position themselves in a different way than in other situations. All three categories that Thompson and Norton (2011) identified represent how consumers may assign a higher conditional value to products and like to mark their status when they are in a formal situation. In order to establish their status in the eyes of others, consumers need to engage in a similar consumption pattern 
consistently, which will increase their purchase quantity. Therefore, I formulate the following hypothesis:

H5b: Conditional value (related to formalization of situation) is positively associated with the quantity purchased.

\section{2 - The Moderating Effect of Conditional Value (related to formalization of situation)}

\subsection{1 - The Effect of Conditional Value on Functional Value}

In varying usage situations, the reason to purchase a product may change or the structure of a specific situation may change the end result (Belk, 1975; Luo, 2005).Although consumers' consumption values for products will stay the same, the situation they are involved in will likely change how they perceive the value of a product.

The conditional value of a product will likely be perceived as higher by consumers in higher levels of formalized contexts. In this case, the higher perceived conditional value will likely moderate the positive relationship between functional values and consumers' willingness to pay. When consumers are in formalized contexts, such as graduation ceremonies or weddings, they are likely to spend more on a product that they need. In such scenarios, the relationship between functional value and purchasing decisions will likely to be strengthened since the situation will determine how they perceive the value of a product; this in turn will lead to a change in their willingness to pay or the quantity they purchase.

In different situations, consumers may assign different levels of functional value to products, and in formal settings, context cues may play a role in how consumers perceive the product in terms of how it performs or what it does. In formalized contexts, the conditional value of a product will likely moderate the relationship between the 
perceived functional value and consumers' willingness to pay because consumers want a product to 'fit' with the usage situation (Lai, 1991). For decisions that do not take into account the intended usage situation, the perceived functional value of a product may be weaker. For instance, a consumer may purchase a less expensive bottle of wine, or he/she may decide to purchase a bottle of wine that he/she enjoys the taste of; however, if he/she were to throw a party, then the choice of wine would change. Since the contextual setting at a party is more formalized than personal use at home (Morand, 1995), the relationship between the perceived functional value of the product and the willingness to pay would be moderated by the effect of its conditional value. The host would select a well-known wine for her friends and would be willing to spend extra money on acquiring it; or he/she may choose a bottle of wine that has many nutritional benefits. Therefore, I formulate the following hypothesis:

H6.1a: The positive relationship between perceived functional value and consumers' willingness to pay will be moderated by the perceived conditional value (related to formalization of situation).

The situational factors should strengthen the relationship between perceived functional value and purchase quantities because consumers would want to be consistent with their choice of product. Since functional value represents how well a product performs as a gift or for personal use, how healthy it is, or how well it satisfies a consumer's wants and needs (Sheth, Newman, \& Gross, 1991; Chen, Chang, \& Chang, 2005), then in more formalized contexts, a consumer would want to choose a wine that suits the occasion best in terms of its functional use. For instance, for a birthday party, a consumer may perceive higher functional value in a bottle of wine with regards to how 
well it goes with or without food. Another consumer may perceive higher functional value in how easy the bottle of wine is to drink in formal social events. In such scenarios, a consumers' purchase quantity of the product will increase because the situational cues will change what they look for and how they perceive these specifications in terms of functional value. Therefore, I formulate the following hypothesis:

H6.1b: The positive relationship between perceived functional value and consumers' purchase quantity will be moderated by the perceived conditional value (related to formalization of situation).

\subsection{2 - The Effect of Conditional Value on Symbolic Value}

I expect that the positive relationship between symbolic values and consumers' willingness to pay will grow stronger when the level of formality in a situation is higher. When a consumer is engaged in a formal situation, he/she may hold higher conditional values which could impact how he/she is making a decision with regards to his/her value assessment of a certain product in terms of its symbolic value.

Formal situations involve certain structures and rules (Morand, 1995) which increase the perceived conditional value of a product; thus, the relationship between perceived symbolic value a consumer assigns to a product and willingness to pay will likely be enhanced depending on the formality of the situation because values are employed by an individual so that he/she can make appropriate decisions (SanchezFernandez \& Iniesta-Bonillo, 2007). Consumers often prefer to present themselves in different ways or impress others around them (Ashworth \& Matear, 2009) by acting different ways in different contexts. The level of formality in certain situations will likely increase the perceived conditional value, which in turn will likely moderate the 
relationship between how consumers assign symbolic value to products when the context is highly formalized and how consumers will likely increase their willingness to pay for a product if it helps them symbolize an accomplishment (Heaney, Goldsmith, \& Jusoh, 2005).

In formalized contexts, perceived conditional value will likely moderate the relationship between the perceived symbolic value and the willingness to pay of consumers because in such contexts, consumers will likely assign higher symbolic values to products because they would want the product to deliver the intended message, such as wealth, sophistication, education, or socially responsible behavior (Moav \& Neeman, 2010). In situations where the formalization is high, perceived conditional value will likely be higher, and when consumers want to symbolize a certain meaning through their purchases, the relationship would be moderated by the perceived conditional value in different usage situations. A consumer may purchase a more expensive bottle of wine at a formal event, whereas the same consumer would not spend as much at an informal event. Therefore, I formulate the following hypothesis:

H6.2a: The positive relationship between perceived symbolic value and consumers' willingness to pay will be moderated by the perceived conditional value (related to formalization of situation).

The influence of conditional value will likely impact the relationship between perceived symbolic value and purchase quantity for consumers. In formalized contexts, consumers' perception of symbolic value may change. It may include more symbolizing or signaling of messages to others (Naald \& Cameron, 2011; Graham \& Bansal, 2007). When this is the case, consumers tend to want to keep their message consistent in 
different situational contexts. In order to deliver the same, consistent message, consumers will likely purchase more of an item, which also shows that the relationship between the perceived symbolic value of a product and consumers' purchase quantity will likely be moderated by the level of formalization.

Secondly, in formal situations, consumers may engage in status consumption. According to Banks' (2010) study, consumers tend to purchase high status objects to signal their class standing and by forming these regular patterns, they believe that they will signal a consistent message. When consumers perceive the situation as highly formalized, the perceived conditional value will likely be higher and consumers will likely try to signal their status to others in order to create a sense of belonging to the group (Kropp, Lavack, \& Silvera, 2005); they will assign higher symbolic value to products, which in turn will increase the purchase quantity in order to keep the message consistent. Therefore, I formulate the following hypothesis:

H6.2b: The positive relationship between perceived symbolic value and consumers' purchase quantity will be moderated by the perceived conditional value (related to formalization of situation).

\subsection{3 - The Effect of Conditional Value on Emotional Value}

The positive relationship between perceived emotional value and willingness to pay for a product will be strengthened by the moderating effect of perceived conditional value in formalized settings because the role of emotion in purchasing decisions encompasses the core value consumers receive (Barlow \& Maul, 2010). Consumers may try to create links between their emotions and the current consumption situation. When consumers perceive that a situation is highly formalized, the perceived conditional value 
of a product may increase; therefore the perceived conditional value will likely moderate the relationship between perceived emotional value and the willingness to pay. For instance, if a consumer were to purchase an anniversary gift that will be given during the anniversary party or dinner, emotions would play a bigger role in this context because the formalization of the situation would be higher. For the formalized situation, the consumer would want to purchase a product that represents their affection the best; in turn, he/she would be willing to spend more on a product that satisfies this goal in terms of the situational requirements.

When consumers are engaged in formal situations, the situational factors in these contexts are likely to have an effect on how they perceive emotional value in a product. Consumers link certain products with cues that they have in their memories. When consumers think nostalgically, they tend to think about positive memories so that their self-regard increases (Zauberman, Ratner, \& Kim, 2008). The formality of a situation will moderate the effect of their willingness to pay for a product in such a way that consumers would make more favorable attributions to products that they perceive as providing them with a familiar feeling when certain contextual cues are present.

In formalized contexts, consumers may feel more comfortable consuming a product. This also reflects the emotional value they assign to the item. For instance, if a consumer were to be involved in an organized function, he/she may prefer to order a glass of wine that he/she is familiar with so that he/she does not regret the decision for the rest of the event. Schwartz et al. (2002) also suggest that in different situational settings, consumers tend to try to optimize the pleasure of the decision in order to prevent regret. Under such circumstances, these decisions reflect how situational factors would 
have a strengthening effect on the relationship between the perceived emotional value of the product and consumers' willingness to pay. Therefore, I formulate the following hypothesis:

H6.3a: The positive relationship between perceived emotional value and consumers' willingness to pay will be moderated by the perceived conditional value (related to formalization of situation).

Consumers' emotions play a big role in their purchase quantities and formal situations will likely moderate the effect of this positive relationship. For instance, if a consumer were to go on a first date with someone to a movie theatre, although it sounds like a casual night out, the situation's formality is high due to the nature of a "first date." If the same consumer were to go to the same movie theatre another time, contextual cues would remind him/her about the first date, which would arouse certain emotions (Ford \& Merchant, 2010).In line with Mizerski and White's (1986) and Burnett and Lunsford's (1994) studies, this arousal of emotions, due to the different contextual cues, would influence consumers' purchasing decisions.

Situational factors will likely moderate the relationship between pleasant memories that are associated with the context and the consumers' purchase quantity. Consumers will likely see that there is a higher perceived emotional value when the usage situation evokes personal nostalgia (Posavac, Herzstein, \& Sanbonmatsu, 2003; Dube, Cecile-Cervellon, \& Jingyuan, 2003; Ford Merchant, 2010). This personal nostalgia from certain context cues may trigger certain responses to a product which in turn may moderate the effect of perceived emotional value on purchase quantities. For example, if a consumer were to walk into a store where the layout of the store brought back some 
previous memories, then the situational cues would strengthen the effect of perceived emotional value on purchase quantity.

Lastly, hedonic tone of consumption affects a consumer's purchase quantity (Posavac, Herzstein, \& Sanbonmatsu, 2003), and different events may arouse different affective states. Iyengar and Lepper (1999) also suggest that in particular situations, consumers tend to choose the option that their significant other offers them. In this context, consumers may perceive higher conditional value in certain scenarios, and how they assign a higher emotional value to a product and how they choose the product are moderated by the perceived conditional value. Therefore, I hypothesize that:

H6.3b: The positive relationship between perceived emotional value and consumers' purchase quantity will be moderated by the perceived conditional value (related to formalization of situation).

\subsection{4 - The Effect of Conditional Value on Epistemic Value}

The relationship between the perceived epistemic value and consumers' willingness to pay for a product will be strengthened if consumers are engaged in a situation where the formalization is higher than at other times. The perceived epistemic value of a product will be high if the product is perceived as novel, informative, or unique (Blake et al., 1973; Sheth, Newman, \& Gross, 1991; Meyer, Zhao, \& Han, 2008). When consumers perceive higher conditional value in certain contexts, it will likely moderate the relationship between the perceived epistemic value and consumers' willingness to pay.

When combined with different contextual cues, consumers' assessment of the epistemic value and how it may lead to different levels of willingness to pay for a product 
may change. For instance, if consumers are engaged in a more formalized setting where they are having wine with fellow co-workers, they may want to learn new things about a wine that their colleague suggested which will likely increase the perceived epistemic value of that specific bottle of wine. In such contexts, perceived conditional value will likely moderate the relationship between the perceived epistemic value of the product and consumers' willingness to pay, and consumers may choose a different type of wine in order to learn something new about the product. When consumers are in different consumption settings, the relationship between the perceived epistemic value and the willingness to pay for the product will likely differ, accordingly.

Consumers need to be informed in order to appreciate what a new product has to offer them (Depositario, Nayga, Wu,\& Laude, 2009). If consumers perceive that a certain formal event will provide them with an opportunity to enhance their knowledge about a certain item, the perceived epistemic value of the product will likely be higher. For instance, if consumers are bored with their current product choice, they may read newsletters to figure out if there is anything out there that is worth trying or purchasing. They may attend formal wine tasting events, and as a result, these consumers may assign higher epistemic values to different wines than if they just saw them at a store. Thus, more formalized contexts will likely enhance the perceived epistemic value of a product and increase consumers' willingness to pay.

Lastly, the relationship between consumers' perceived epistemic value of a product and their willingness to pay may be moderated by situational factors in such a way that when consumers are in need of a novel item, they may rely on contextual cues such as the signs at the store, how the store looks, or the shape or the packaging of the 
product. Salespeople and other consumers in the store will also shape how they perceive the product. When contextual factors are more structured and seen as more formalized compared to daily life routines, the perceived conditional value will likely increase and in turn will likely increase a consumer's assessment of the epistemic value and their willingness to pay for the item. Therefore, I formulate the following hypothesis:

H6.4a: The positive relationship between perceived epistemic value and consumers' willingness to pay will be moderated by the perceived conditional value (related to formalization of situation).

Consumers may purchase higher quantities of a product when they are involved in varying levels of formalized situations. These differences in different contexts will likely affect how they perceive the newness of the product, in turn how it will change their purchase quantity. For instance, a consumer may purchase more of a new product if he/she was bored with his/her current choice. In addition, different situations may require consumers to choose a different type of product than their regular choice. For instance, a consumer might order a different glass of wine when he/she is with co-workers than if he/she is with family. The differences in choice in these situations show that the perceived conditional value will likely increase and moderate how consumers perceive epistemic value, and in turn will likely affect the purchase quantity of an item.

Situations with varying levels of formalization will require consumers to make different choices. Some situations may require consumers to be more knowledgeable; other times the situation may require consumers to be interested in a product. For instance, if a consumer is involved in attending different wine tasting events, then he/she may perceive higher epistemic value in such events and, as a result, may read more about 
them or learn new things before his/her social circle. Therefore, different situations will increase the perceived conditional value and will trigger different aspects of learning or information seeking, which will in turn increase the perceived epistemic value in products and increase the purchase quantity. Therefore, I formulate the following hypothesis:

H6.4b: The positive relationship between perceived epistemic value and consumers' purchase quantity will be moderated by the perceived conditional value (related to formalization of situation).

\section{1 - Sample and Data Collection}

\section{RESEARCH METHODOLOGY}

To ensure the wide applicability of my findings, I tested my hypotheses with a sample of 202. I used a single-respondent design and obtained the contact information of consumers to whom I sent the surveys. The participants were randomly chosen from the general wine consumer population; the age range was between 20 and 75, and included both males and females. There were 83 male respondents and 119 female respondents, which represents $41.1 \%$ and $58.9 \%$ of my total sample, respectively. There were 74 single and 128 married respondents. The percentages for the marital status are $36.6 \%$ and $63.4 \%$, respectively.

My data collection relies on Dillman's (1978) total design method. I prepared a mailing packet containing a cover letter addressed personally to the respondent, a questionnaire, and a postage-paid return envelope. In total, I sent out 800 surveys to potential respondents and received 268 responses back, for a response rate of $33.5 \%$, which is consistent with other studies pertaining to consumer behavior and consumers' 
consumption habits. When I assessed the returned surveys, 202 of them were usable in my analysis.

As mentioned earlier, I used wine purchases in my study. Wine is an experiential product (Mueller, Lockshin, \& Louviere, 2010) and is thus an appropriate product to fully capture the effects of epistemic and conditional values. For instance, previous research either studied durable products or service encounters; as a result, they could not measure the effect of epistemic and conditional values. As it is an experiential product, wine is appropriate since it can arouse curiosity and novelty and, in formalized settings, its usage could change with regards to the consumer's consumption plans.

\subsection{1 - Measures of Constructs}

In Table 1, I list the measures used in my analysis, detailing their individual items, overall reliability estimates, Cronbach's alpha, Composite Reliability (CR), and Average Variance Extracted (AVE). When studying my data, I used the following formulas in order to estimate the numbers employed in my study.

Cronbach's alpha $(\boldsymbol{\alpha})$ is a coefficient of reliability or consistency index. It is commonly used as a measure of the internal consistency or reliability of test scores for a sample. Cronbach's alpha ranges from 0 to 1 ; the higher the average inter-term correlation, the greater the value of $\alpha$, reflecting a higher internal consistency for the index. In many cases, a value of 0.7 or higher is considered acceptable. For this study, $\alpha$ values are higher than 0.8 . This means that the internal consistency or index reliability of my sample is very good.

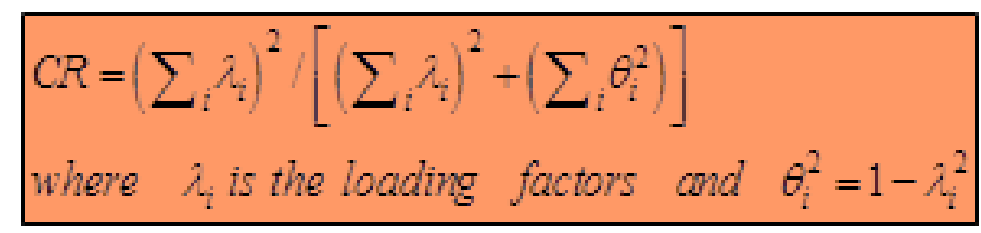


Construct Reliability(CR) is calculated using the above formula for each construct in this study. Icalculated the sum of the loading factors for each construct item and then calculated the square of this sum. Next, I calculated each $\Theta_{\mathrm{i}}^{2}$, which is the variance of the measured parameters of the construct item. (This figure reflects the measurement error of the measured parameters.) Then, I summed up all findings of $\Theta_{i}{ }^{2}$ for that specific construct item. Finally, I put these found values into the formula and found the construct reliability value for each construct item.

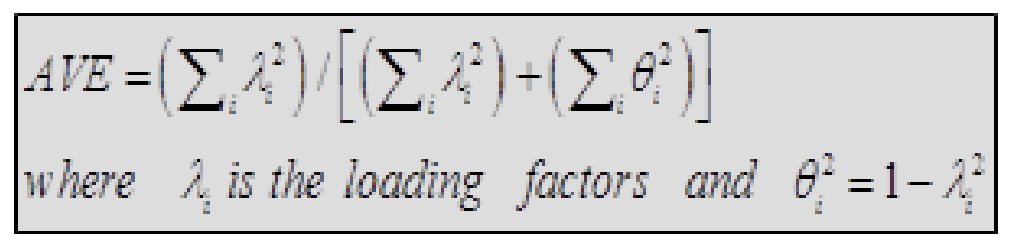

Average Variance Extracted (AVE) is calculated using the above formula for each construct in this study. First, I calculated the square of each loading factor for the each measurement of each specific construct item. Then, Isummed up the squared values of each construct item. Next, I calculated each $\Theta_{i}{ }^{2}$, which is the variance of the measured parameters of the construct item. (This figure reflects the measurement error of the measured parameters). I summed up all findings of $\Theta_{i}{ }^{2}$. Then, I summed each construct item. Finally, I put these values into the formula and found the Average Variance Extracted value for each construct item.

In line with my research focus, my measures assess respondents' purchasing decisions and the relationships among the constructs of consumer value systems, usage situation, and purchasing decisions in terms of quantity purchased and willingness to pay for a certain product. A Likert's 7-point scale ranging from strongly disagree (1) to 
strongly agree (7) is utilized for all of the five dimensions of consumer value (functional, symbolic, emotional, epistemic, and conditional).

Functional Value: I measure the functional value using a seven-item scale which reflects the strength of the relationship between the perceived utility of a product and the purchasing decisions of consumers. The perceived functionality of the product could be in the form of its ease of use, benefits to consumers, how it performs (Sheth, Newman, \& Gross, 1991), and how easily it can be accessed.

Symbolic Value: I measure symbolic value using a four-item scale that reflects the extent to which consumers' purchasing decisions vary on the basis of the symbolic value they assign to products. These symbolic values could be in the form of how much they perceive the product to be prestigious (Shukla, 2009), unique compared to other similar products, elegant, or stylish.

Emotional Value: Following Sheth, Newman, and Gross (1991) and MacKay (1999), I measure emotional value with a five-item scale that assesses whether perceived emotional value changes consumers' purchasing decisions, such as if consumers purchase a product based on memories of their parents giving them the item as a gift in their childhood.

Epistemic Value: I measure epistemic value using four items that reflect the extent to which consumers' decisions are affected by their knowledge of wine, the novelty of the wine, or their willingness to try or experience a new type of wine. Since wine is an experiential product (Mueller, Lockshin, \& Louviere, 2010), consumers assign a higher epistemic value to a new brand of wine. 
Conditional Value: I measure conditional values using a five-item scale that assesses whether the level of formality in certain contexts affect how consumers perceive the conditional value of products. The formalization of situations is characterized by a more structured setting such as business meetings (Morand, 1995), and formality will likely have an effect on consumers' purchasing decisions.

Willingness to Pay: I measured the willingness to pay of consumers by looking at the dollar amount spent per bottle with regards to how consumers perceived the value they receive from the product and how it changed how much they were willing to pay for a bottle of wine.

Purchase Quantity: I measured the quantity that consumers purchased by looking at how many bottles of wine they consumed per month with regards to the perceived values a product may have had.

Control Variables: I included three control variables to avoid misspecification and to take into account possible alternative explanations for variations in purchasing decisions. In my study, I control for gender, marital status, and age. The reason that they are used as control variables is that they are inherently changeable (Shuttleworth, 2008). Since I am studying both genders, controlling for gender provides the opportunity to account for variance caused by gender (Atinc, Simmering, \& Kroll, 2011). Secondly, I asked for the marital status of my respondents. The reason I use marital status as a control variable is that I will be able to check for any differences it may create when I am doing my study. Lastly, I controlled for the age of the respondents. 
Table 1 - Construct and Measurement Items

\begin{tabular}{|c|c|c|}
\hline & $\begin{array}{l}\text { Factor } \\
\text { loading }\end{array}$ & t - value \\
\hline \multicolumn{3}{|l|}{ Functional Value $(\alpha=0.959, \mathrm{CR}=0.954, \mathrm{AVE}=0.748)$} \\
\hline Wine makes a perfect gift for many occasions. & 0.810a & \\
\hline I find wine easy to drink. & $\mathbf{0 . 8 8 3}$ & 16.908 \\
\hline Wine appeals to me with many benefits other than just being an accompaniment to food. & 0.877 & 16.646 \\
\hline Drinking wine is good for your health. & 0.872 & 16.572 \\
\hline Wine satisfies my thirst and my appetite. & 0.891 & $\mathbf{1 7 . 2 6 6}$ \\
\hline My favorite wines are easily accessible and comfortable. & $\mathbf{0 . 8 5 3}$ & 15.908 \\
\hline My favorite wines go well with or without food. & 0.866 & 16.288 \\
\hline \multicolumn{3}{|l|}{ Symbolic Value $(\alpha=0.938, \mathrm{CR}=0.938, \mathrm{AVE}=0.792)$} \\
\hline Drinking wine makes me feel prestigious & 0.885a & \\
\hline Drinking wine makes me feel unique as compared to drinking other alcoholic beverages & 0.846 & $\mathbf{1 6 . 8 6 3}$ \\
\hline Drinking wine makes me feel elegant and glamorous & 0.907 & $\mathbf{1 9 . 5 8 8}$ \\
\hline Drinking wine makes me feel stylish & $\mathbf{0 . 9 2 0}$ & 20.449 \\
\hline \multicolumn{3}{|l|}{ Emotional Value $(\alpha=0.845, \mathrm{CR}=0.836, \mathrm{AVE}=0.506)$} \\
\hline Drinking wine soothes me. & 0.639a & \\
\hline Drinking wine makes me feel comfortable and relaxed & $\mathbf{0 . 7 2 8}$ & 8.609 \\
\hline Drinking wine gives me pleasure. & 0.779 & 9.011 \\
\hline I find drinking wine enjoyable. & 0.734 & 8.564 \\
\hline Drinking wine makes me happy & 0.668 & 7.968 \\
\hline \multicolumn{3}{|l|}{ Epistemic Value $(\alpha=0.869, \mathrm{CR}=0.867, \mathrm{AVE}=0.620)$} \\
\hline I am curious about wines that I have not yet tried. & 0.768a & \\
\hline I like to try wines that I have never tasted before. & 0.792 & 11.005 \\
\hline I started drinking wine because I wanted to learn more about it & 0.800 & $\mathbf{1 1 . 1 8 1}$ \\
\hline I try to find out everything I can about the wines I drink. & 0.790 & $\mathbf{1 1 . 5 2 3}$ \\
\hline \multicolumn{3}{|l|}{ Conditional Value $(\alpha=0.889$, CR $=0.906$, AVE $=0.660)$} \\
\hline Drinking wine with co-workers. & 0.724a & \\
\hline Drinking wine at formal social events. & $\mathbf{0 . 8 4 2}$ & 9.820 \\
\hline Drinking wine with a new associate/acquaintance. & 0.801 & 11.000 \\
\hline Drinking wine at business related functions. & 0.862 & $\mathbf{1 1 . 5 9 7}$ \\
\hline Drinking wine at formal wine tastings. & $\mathbf{0 . 8 2 5}$ & 9.952 \\
\hline
\end{tabular}

Notes: a Initial loading was fixed to 1 to set the scale of the construct.

$\alpha=$ Cronbach's alpha; $\mathrm{CR}=$ construct reliability; $\mathrm{AVE}=$ average variance extracted .

\subsection{2 - Assessing the Reliability and Validity of Measures}

In line with Anderson and Gerbing (1988), I estimated a five-factor measurement model using AMOS 6.0. Confirmatory factor analysis (CFA) reveals factor loadings greater than 0.60 , normalized residuals less than 2.58 , and modification indices less than 3.84 (Anderson \& Gerbing, 1988). These results suggest that no deletions of scale items are needed to improve model fit. I also note that the measurement model fits the data well: $\chi^{2}(238)=315.93$, goodness-of-fit index $(\mathrm{GFI})=0.90$, Tucker-Lewis index $(\mathrm{TLI})=$ 
0.97, confirmatory fit index $(\mathrm{CFI})=0.98$, and root mean squared error of approximation $($ RMSEA $)=0.04$

I confirm the convergent validity of my scales with the significant factor loadings in the measurement model ( $>2.0$, Gerbing \& Anderson, 1988) and the magnitude of my AVE estimates (equal to or greater than 0.50, Bagozzi \& Yi, 1988). Several assessment criteria also support the discriminant validity of my constructs. None of the confidence intervals for the correlations between constructs includes $1.0(\mathrm{p}<0.05)$ (Anderson \& Gerbing, 1988), and the AVE estimates of the constructs are greater than the squared correlations between the corresponding pairs of constructs (Fornell \& Larcker, 1981).

\section{2 - Analysis \& Results}

I provide the correlations and descriptive statistics for the study variables in Table 2. I use hierarchical regression and mean centering as a way of mitigating multicollinearity, and in my study, when I diagnose for collinearity, I see that the condition indexes are less than 10, which suggests that multicollinearity is not an issue. In my correlation matrix, the correlation between functional and symbolic values seems to be higher; however, these variables are not testing the same aspect. The reason that it is higher than expected could be that consumers may appreciate the symbolic value of a product and may purchase the item because they may expect it to convey a message. .

When consumers perceive that the product they purchase will signal or symbolize a certain meaning to others, they may expect the product to do its job satisfactorily, which relates back to the functional value of the product. Consumers may be assigning functional value to the symbolic value of the product. In the matrix, I see that the formal situations also have a high correlation with symbolic values. The reason may be that, in 
general, when consumers are involved in a formal situation, they will likely try to impress others (Ashworth \& Matear, 2009) or signal status (Shukla, 2009), or they may simply want to follow the structure of the formal setting, which may lead them to assign higher symbolic values to items they purchase.

Table 2 - Descriptive Statistics and Correlation Matrix $(n=202)$

\begin{tabular}{|l|c|c|c|c|c|c|c|c|c|c|}
\hline & $\mathbf{1}$ & $\mathbf{2}$ & $\mathbf{3}$ & $\mathbf{4}$ & $\mathbf{5}$ & $\mathbf{6}$ & $\mathbf{7}$ & $\mathbf{8}$ & $\mathbf{9}$ & $\mathbf{1 0}$ \\
\hline 1. Epistemic Value & 1.00 & & & & & & & & & \\
\hline 2. Symbolic Value & $.49^{* *}$ & 1.00 & & & & & & & & \\
\hline 3. Emotional Value & $.41^{* *}$ & $.73^{* *}$ & 1.00 & & & & & & & \\
\hline 4. Functional Value & $.45^{* *}$ & $.86^{* *}$ & $.73^{* *}$ & 1.00 & & & & & & \\
\hline 5. Conditional Value & $.43^{* *}$ & $.78^{* *}$ & $.63^{* *}$ & $.79^{* *}$ & 1.00 & & & & & \\
\hline 6. Purchased Quantity & $.51^{* *}$ & $.79^{* *}$ & $.72^{* *}$ & $.77^{* *}$ & $.75^{* *}$ & 1.00 & & & & \\
\hline 7. Willingness to Pay & $.53^{* *}$ & $.73^{* *}$ & $.65^{* *}$ & $.66^{* *}$ & $.71^{* *}$ & $.76^{* *}$ & 1.00 & & & \\
\hline 8. Gender & -.04 & -.00 & -0.01 & -.01 & -.02 & 0.09 & -0.04 & 1.00 & & \\
\hline 9. Marital Status & -.11 & $-.26^{* * *}$ & $-.35^{* * *}$ & $-.30^{* * *}$ & $-.27^{* * *}$ & $-.27^{* * *}$ & $-.28^{* * *}$ & .01 & 1.00 & \\
\hline 10. Age & $.17^{*}$ & $.30^{* *}$ & $.38^{* *}$ & $.31^{* *}$ & $.36^{* *}$ & $.39^{* *}$ & $.33^{* *}$ & $.17^{*}$ & $-.50^{* *}$ & 1.00 \\
\hline \multicolumn{1}{|c}{ Std. Deviation } & 3.73 & 4.72 & 5.26 & 4.82 & 4.37 & 7.83 & 18.07 & 0.41 & 0.37 & 36.22 \\
\hline \multicolumn{1}{r|}{1.06} & 1.42 & .78 & 1.51 & 1.37 & 6.39 & 7.12 & 0.49 & 0.48 & 14.28 \\
\hline
\end{tabular}

** Correlation is significant at the 0.01 level (2-tailed).

* Correlation is significant at the 0.05 level (2-tailed).

In Table $3 \mathrm{a}$ and $3 \mathrm{~b}$, I provide the regression results. Model 1 contains only the control variables; Model 2 adds the direct effect of epistemic, symbolic, functional, and emotional values; and Model 3 adds the formal situation factor in play. In Table 3a, it is evident that both Model 2 and 3 reveal a significant improvement in model fit for willingness to pay ( $\Delta R^{2}=0.47$ and 0.036 , respectively), attesting to the importance of the variables representing my hypotheses. In Table $3 a$, it is evident that gender and marital status have a significant negative impact on consumers' willingness to pay for a bottle of wine. Age, as the third control variable, has no significant effect on the dollar amount spent per bottle. In Model 2, for willingness to pay, all consumption values except functional value play a significant role in the dollar amount spent on a bottle of wine. These results also show support for my hypotheses H2a, H3a, and H4a. Although positive, functional value does not seem to have a significant effect on consumers' 
willingness to pay. The results in Model 3 also support H5a, which posits that conditional value (related to formalization of situation) is positively associated with consumers' willingness to pay. Model 4 displays the results for my interaction effects. In H6.1a, H6.2a, H6.3a, and H6.4a, I predicted that high levels of conditional value would have a positive effect on consumption values, and thus, consumers' willingness to pay would be positively affected. Model 4 shows that the moderating effect of conditional value on perceived functional value is not significant; on the other hand, the symbolic, emotional, and epistemic values are positively affected by high levels of formalization in situations.

Therefore, this supports my hypotheses H6.2a, H6.3a, and H6.4a.

Table 3a - Regression Analysis for Willingness to Pay

\begin{tabular}{|c|c|c|c|c|}
\hline & Model 1 & Model 2 & Model 3 & Model 4 \\
\hline Gender $^{a}$ & -1.156 & -0.554 & -0.372 & -0.670 \\
\hline Marital Status $^{b}$ & $-2.143^{+}$ & -0.592 & -0.700 & -0.829 \\
\hline Age & $0.133^{* *}$ & 0.034 & 0.013 & $0.001^{* *}$ \\
\hline Hla: Functional Value & & 0.052 & -0.619 & -0.122 \\
\hline$H 2 a$ : Symbolic Value & & $2.295^{* * * * *}$ & $1.681^{* *}$ & $1.846^{* *}$ \\
\hline H3a: Emotional Value & & $1.590^{*}$ & $1.612^{*}$ & $1.478^{* *}$ \\
\hline$H 4 a:$ Epistemic Value & & $1.426^{* * *}$ & $1.338^{* * *}$ & $1.439^{* * * *}$ \\
\hline H5a: Conditional Value & & & $1.736^{* * * *}$ & $1.424^{* * * *}$ \\
\hline H6.1a: Functional Value X Conditional Value & & & & -0.429 \\
\hline H6.2a: Symbolic Value X Conditional Value & & & & $0.923^{* *}$ \\
\hline H6.3a: Emotional Value X Conditional Value & & & & $0.908^{*}$ \\
\hline H6.4a: Epistemic Value X Conditional Value & & & & $0.482^{*}$ \\
\hline R-square & 0.131 & 0.601 & 0.636 & 0.724 \\
\hline$\Delta \mathrm{R}$-square & & $0.470^{* *}$ & $0.036^{* * * *}$ & $0.088^{* * * *}$ \\
\hline
\end{tabular}

Notes: Unstandardized coefficients (two-tailed $p$-values).

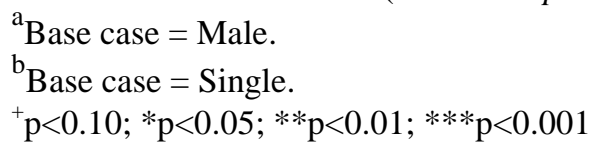

Table $3 \mathrm{~b}$ shows that gender has a positive interaction with the number of bottles purchased per month. Although the effect is insignificant, gender and age do affect the purchase quantity. It is also evident that marital status has a significantly negative effect on the number of bottles purchased per month. Models 2 and 3 in Table $3 b$ reveal a 
significant improvement in model fit for quantity purchased $\left(\Delta R^{2}=0.557\right.$ and 0.016 , respectively, $\mathrm{p}<0.05$ ), consistent with the basic premise of my theoretical discussion that consumption values play a positive role in consumers' purchasing decisions. The symbolic values consumers assign to products have a statistically significant effect on the number of bottles purchased per month, which supports my hypotheses H2b. Although the effect is less significant than symbolic values, emotional, epistemic, and functional values also have a positive effect on the number of bottles purchased per month, which supports my hypotheses H1b, H3b, and H4b. The results in Model 3 also support H5b, which posits that conditional value (related to formalization of situation) is positively associated with the quantity purchased. Model 4 displays the results for my interaction effects. In hypotheses H6.1b, H6.2b, H6.3b, and H6.4b, I predicted that high levels of conditional value would have a positive effect on consumption values, and subsequently that purchase quantity would be positively affected. Model 4 shows that all consumption values are positively affected by high levels of formalization in situations. Thus, this provides support for my hypotheses H6.1b, H6.2b, H6.3b, and H6.4b. 
Table 3b - Regression Analysis for Purchase Quantity

\begin{tabular}{|c|c|c|c|c|}
\hline & Model 1 & Model 2 & Model 3 & Model 4 \\
\hline Gender $^{\mathrm{a}}$ & 0.449 & $1.015^{*}$ & $1.123^{*}$ & $0.710^{+}$ \\
\hline Marital Status $^{\mathbf{b}}$ & -1.328 & 0.472 & 0.408 & -0.096 \\
\hline Age & $0.148^{* * *}$ & $0.050^{*}$ & $0.037^{+}$ & $0.028^{+}$ \\
\hline$H 1 b:$ Functional Value & & $0.884^{* * *}$ & 0.483 & $1.521^{* * *}$ \\
\hline$H 2 b:$ SymbolicValue & & $1.620^{* * *}$ & $1.253^{* *}$ & $1.149^{* * *}$ \\
\hline$H 3 b$ :Emotional Value & & $1.764^{* *}$ & $1.777^{* *}$ & $1.692^{* * *}$ \\
\hline$H 4 b:$ Epistemic Value & & $0.868^{* *}$ & $0.815^{* *}$ & $0.818^{* * *}$ \\
\hline$H 5 b:$ Conditional Value & & & $1.037^{* *}$ & $0.626^{*}$ \\
\hline H6.1b:FunctionalValueXConditionalValue & & & & $0.429^{+}$ \\
\hline H6.2b:Symbolic ValueXConditionalValue & & & & $0.439^{*}$ \\
\hline$H 6.3 b$ :EmotionalValueXConditionalValue & & & & $0.702^{* *}$ \\
\hline H6.4b:EpistemicValueXConditionalValue & & & & $0.290^{+}$ \\
\hline R-square & 0.158 & 0.715 & 0.731 & 0.846 \\
\hline$\Delta \mathrm{R}$-square & & $0.557^{*: 3}$ & $0.016^{\text {** }}$ & $0.114^{* * * *}$ \\
\hline
\end{tabular}

Notes: Unstandardized coefficients (two-tailed $p$-values).

${ }^{\mathrm{a}}$ Base case $=$ Male.

${ }^{\mathrm{b}}$ Base case $=$ Single.

${ }^{+} \mathrm{p}<0.10 ; * \mathrm{p}<0.05 ; * * \mathrm{p}<0.01 ; * * * \mathrm{p}<0.001$

To shed further light on the presence and significance of the relationships between the different consumption values and purchasing decisions at varying levels of formalizations in situations, I conducted simple slope analyses for each plot (Aiken \& West, 1991). I found that there is not a statistically significant effect of conditional value on the relationship between functional value and willingness to pay for an item in different situational contexts. On the other hand, there is a positive relationship effect between the perceived functional value and the purchase quantity at higher levels of conditional value. Therefore, I find support for my hypothesis H6.1b. 


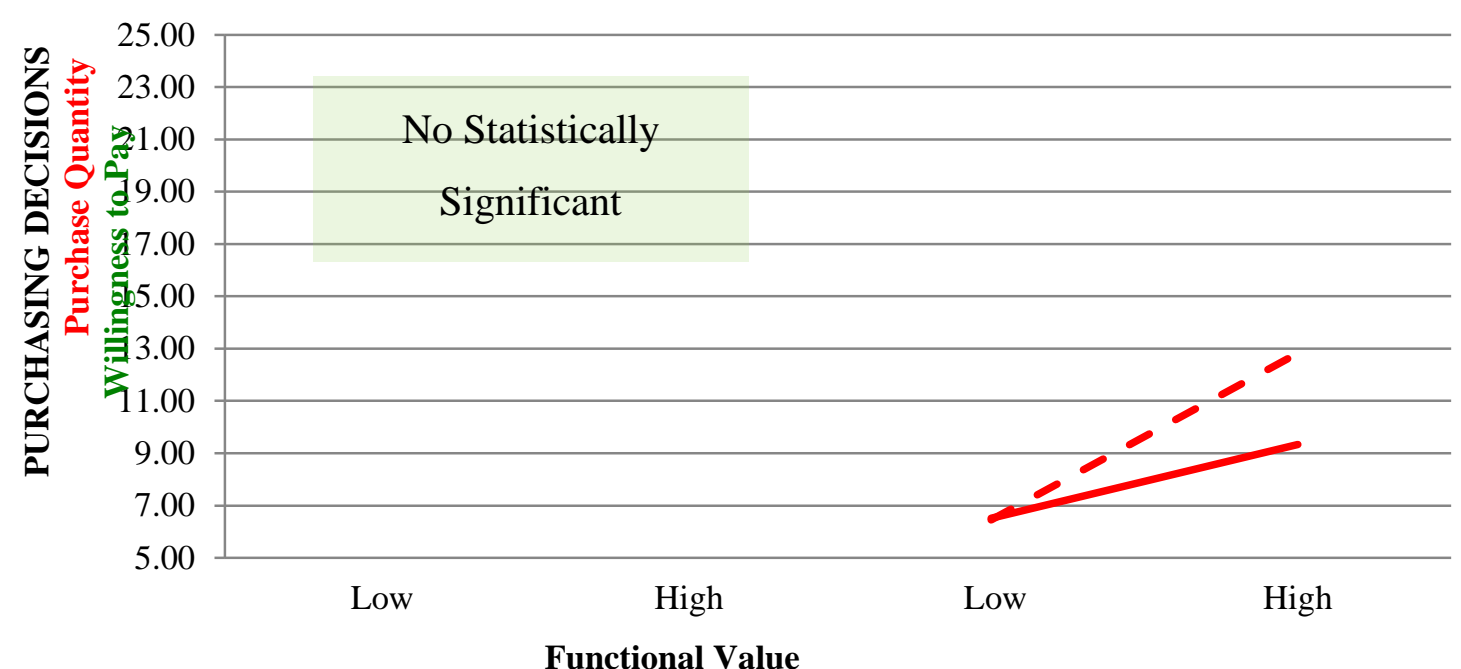

Figure 2 Moderating effect of conditional value on the functional value-purchasing

Conditional Low decisions relationship

Conditional Low - Conditional High

Secondly, I find that (1) there is no significant relationship between symbolic value and willingness to pay at low levels of conditional value, (2) there is a positive relationship between symbolic value and willingness to pay at high levels of conditional value, (3) there is a positive relationship between symbolic value and purchase quantity at high levels of conditional value, and (4) there is no relationship between symbolic value and purchase quantity at low levels of conditional value. Overall, these results support my hypotheses H6.2a and H6.2b. 


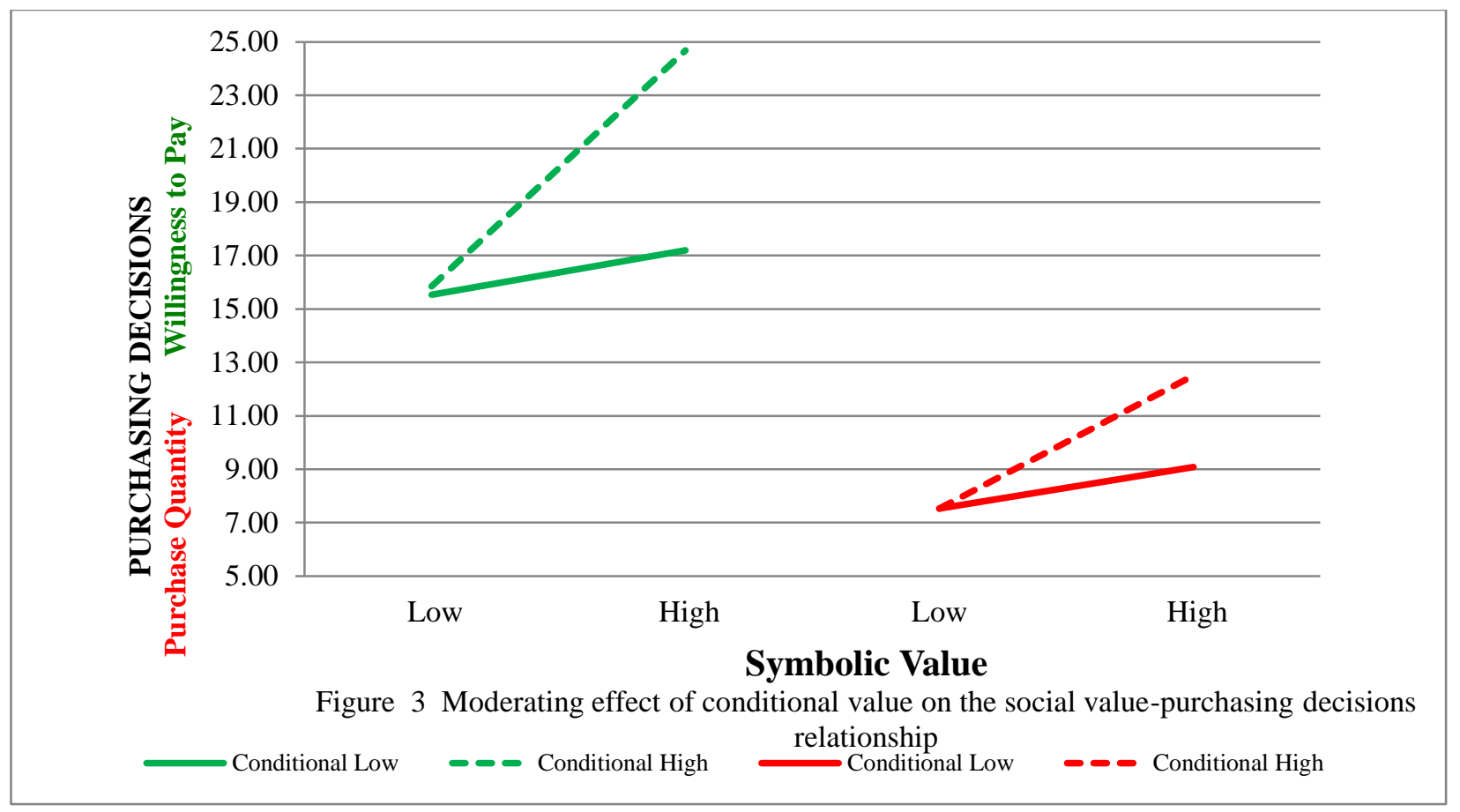

Thirdly, I find that (1) there is not a significant relationship between emotional value and willingness to pay at low levels of conditional value, (2) there is a positive relationship between emotional value and willingness to pay at high levels of conditional value, (3) there is a positive relationship between emotional value and purchase quantity at high levels of conditional value, and (4) there is no relationship between emotional value and purchase quantity at low levels of conditional value. Overall, these results support my hypotheses H6.3a and H6.3b. 


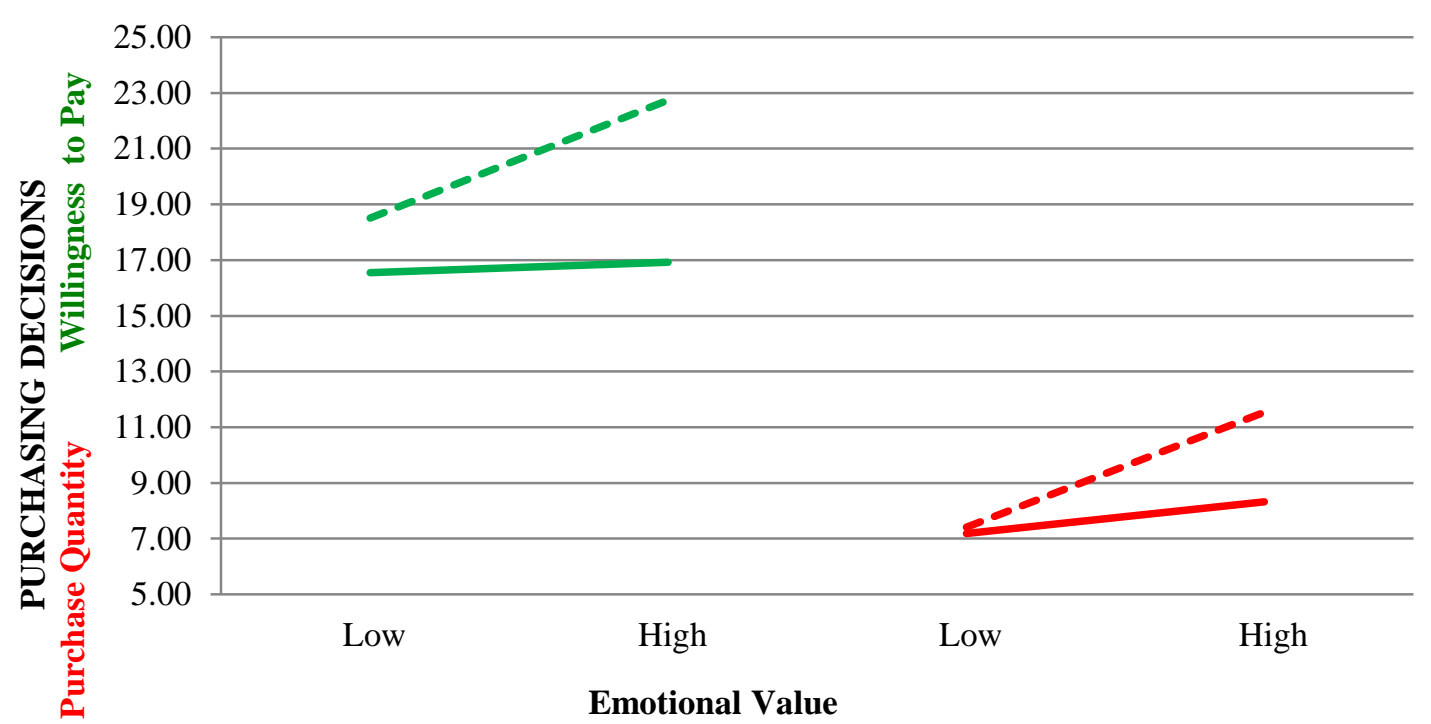

Figure 4 Moderating effect of conditional value on the emotional value-purchasing decisions relationship.

Conditional Low _ Conditional High Conditional High

Lastly, I find that (1) there is no significant relationship between epistemic value and willingness to pay at low levels of conditional value, (2) there is a positive relationship between epistemic value and willingness to pay at high levels of conditional value, (3) there is a positive relationship between epistemic value and purchase quantity at high levels of conditional value, and (4) there is no relationship between epistemic value and purchase quantity at low levels of conditional value. Overall, these results support my hypotheses H6.4a and H6.4b. 


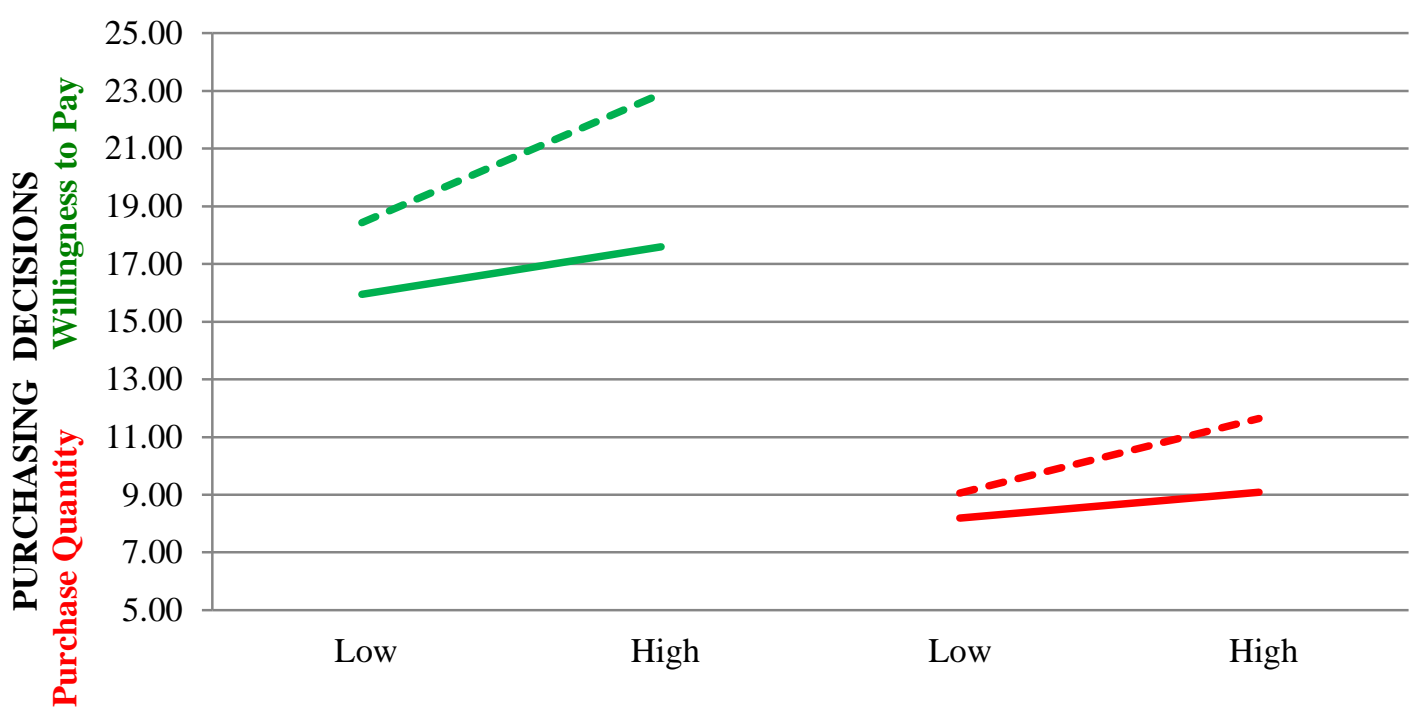

Epistemic Value

Figure 5 Moderating effect of conditional value on the epistemic value -purhasing decisions relationship

Conditional Low $\quad$ - Conditional High Conditional Low $\quad$ - - Conditional High

\subsection{1 - Post-Hoc Analysis}

I undertook a post-hoc analysis to further test the robustness of the regression results. Specifically, to address the on-going debate regarding whether or not the dimensions of consumption value should be treated independently or dependently (Sheth et al., 1991; Sweeney \& Soutar, 2001), I estimated two parallel structural equation models (SEM), equivalent to Model 4 in Tables $3 \mathrm{a}$ and $3 \mathrm{~b}$, with specified covariances among the consumption situation and the four dimensions of consumption value, thereby accounting for their mutual dependence. Both structural equation models offered an appropriate fit, and the sign, magnitude, and significance of the impacts of consumption value dimensions and consumption situation are consistent with those from the previously applied regression analysis.

As an additional check for common method bias, I further compared the results of the two aforementioned structural equation models with comparative SEM models that 
included an added common method factor (Podsakoff et al., 2003). First, I discovered that the chi-square difference between the two models corresponding to Model 4 in Table 3a is not statistically significant $\left(\Delta \chi^{2}(1)=1.09, \mathrm{~ns}\right)$, and only small changes in the size and significance of the paths across the two models emerge. The same pattern of results emerges for the SEM equivalent of Model 4 in Table $3 b$. These results, together with arguments that common method bias is less prevalent in studies that involve highly educated respondents and multi-item scales (Bergkvist \&Rossiter, 2007), alleviate concerns related to the use of a common respondent in this study.

\section{DISCUSSION, THEORETICAL AND MANAGERIAL IMPLICATIONS, AND FUTURE RESEARCH}

\section{1 - Discussion}

My findings extend the current marketing literature in several ways. First, I provide a more elaborate understanding of the relationships between consumer value systems, consumption situations, and purchasing decisions by outlining how the perceived value of a product and different usage situations change a consumer's purchasing decision. Although previous research has established that consumer value systems and different consumption situations affect a consumer's purchasing decisions (Sweeney \& Soutar, 2011; Wood \& Neal, 2009; Shukla, 2009; Sheth et al., 1991; Luo, 2005; Lai, 1991; Corfman et al., 1991; Bearden \& Etzel, 1982), these studies mostly ignore the fact that consumers' purchasing decisions can be affected by both factors simultaneously. Second, by focusing on the effect of these two constructs, I was able to identify how consumers make decisions in different conditions. Also, my study was able

to integrate epistemic value and conditional value in the study, which increases the significance of my findings. Third, I studied the willingness to pay and purchase quantities of consumers as the dependent variables. Prior studies focused on brand loyalty 
(Khalifa, 2004), purchase intentions (Wang, 2010), and cross cultural differences (Grunert \& Scherhorn, 1990). Finally, my study focused on wine products, whereas other studies included either durable products or service encounters.

My findings regarding the direct effect of consumption values show the significant effect these values have on consumers' purchasing decisions. Consumers assign higher functional value to an alternative, if they find it easy to drink, if they observe that the product has many benefits, or if they can distinguish the product by its accessibility. When these factors are higher, consumers assign a higher functional value to the product, which increases their purchase quantity.

My results demonstrate that symbolic value plays an important role in purchasing decisions. When consumers perceive a higher symbolic value in a product, their willingness to pay and purchase quantity increase significantly. Consumers perceive higher symbolic value in a product when they see the item as prestigious, elegant, and/or stylish. Since symbolic values refer to the value a product represents to other people or other groups (Sheth, Newman, \& Gross, 1991), consumers are likely to spend more money in terms of dollar amount on a product with symbolic value and are likely to purchase higher quantities so that they can present their image consistently. In Table 2, the symbolic value and functional value of a product are highly correlated. The reason for this may be due to the function a consumer wants a bottle of wine to serve. For instance, Berthon et al. (2009) state that "brand creation occurs primarily through various forms of communication, which can include any strategy or technique that transfers meaning from one person to another or from a product to a customer" (p. 356). Although my main discussion does not examine brands specifically, Berthon et al. (2009) imply that a 
certain product's value could be the function that a consumer would like to see it perform, such as delivering the message successfully or signifying a status.

The direct effect of emotional values on purchasing decisions is also significant. Perceived emotional value is higher when consumers categorize products in terms of how well they sooth, comfort, give pleasure, and/or promote happiness. Since emotions play a big role in purchasing decisions (Mizerski \& White, 1986; Burnett \& Lunsford, 1994; MacKay, 1999; Tsiros \& Mittal, 2000; Posavac, Herzstein, \& Merchant, 2003; Barlow \& Maul, 2010; Ford \& Merchant, 2010; Kemp \& Kopp, 2011), it is not surprising that when the perceived emotional value is high, consumers' willingness to pay and the quantity they purchase increase. In addition, the perceived epistemic value of products also has a significant effect on consumers' purchasing decisions. Consumers may seek novelty, they may be curious about new offerings, and they may want to learn more about products. When they see a product that satisfies their desire for newness, novelty, or knowledge (Blake et al., 1973; Inman \& Zeelengberg, 2002; De Pelsmacker et al., 2005; Meyer, Zhao, \& Han, 2008; Depositario et al., 2009; Wang \& Xie, 2011), they are willing to spend more on the product and also tend to acquire more of the product. In my survey, respondents assigned higher epistemic values to products when they perceived that they would learn something about the wine or if the wine was new. Consumers also assigned higher values to products if they perceived it in terms of a new experience.

Different situational factors also have a direct and significant effect on consumers' purchasing decisions. These usage situations could involve the place itself (Thomas, 1927; Belk, 1974, 1975; Lutz \& Kakkar, 1975; Houston \& Rothschild, 1978; Thaler, 1985; Chow, Celsi, \& Abel, 1990; Lai, 1991; Triandis, 1994; Rook \& Fisher, 
1995; Quester \& Smart, 1998;Reyneke et al., 2011) or the people around the consumer (Böcker, 1986; Grewal \& Baker, 1994; Kropp, Lavack, \& Silvera, 2005; Luo, 2005; Kaltcheva \& Weitz, 2006; Wood \& Neal, 2009). Consumers tend to follow the norms or rules of a situation so that they do not stand out (Luna \& Gupta, 2001; Grapentine \& Weaver, 2009).In my study, consumers assigned higher conditional value to products when they were engaged in formal activities such as dining with co-workers and attending formal events or business related functions. Since consumers prefer to leave a positive impression (Ashworth \& Matear, 2009), they usually act in line with what the context demands; this is reflected in their willingness to pay for the product and their purchase quantity of the product.

My study also found that a formalized setting does moderate the relationship between consumption values and purchasing decisions. One interesting result is that there was no statistically significant effect of conditional value on the perceived functional value of products. The reason for this could be that in formalized settings, consumers may pay attention to the image or search attributes of the product rather than its physical attributes (Hoon Ang, 2000). In such situations, consumers may want to signal a message, show affection, or learn new information rather than focusing on the tangible characteristics of the product. Since other people's opinions or views usually matter in situational contexts, consumers may be more inclined to rely on interpersonal influence, personal experience, familiarity, or the need for novelty than at other times. As expected, perceived symbolic value, emotional value, and epistemic value were strengthened by situational factors. Consumers' perceptions of symbolic value change in different environments because consumers may appreciate a product that is more prestigious so 
that they can symbolize their self-identity by choosing to purchase the product. The perceived emotional value changes in varying contexts because different situations may arouse different feelings in consumers. Consumers may want to purchase a product that they are comfortable with in situations where the product would offer the only comfort they have. Other contextual cues may trigger pleasant memories so that the consumer associates the pleasantness with the product, which thus increases its perceived emotional value. Lastly, the perceived epistemic value of a product increases in different settings because varying consumption situations may involve novelties and uniqueness. Consumers who seek newness or an interesting characteristic in a product will also likely perceive higher epistemic value in situations where the situational factors are different. If consumers attend a formal wine tasting event, they may purchase the newer wines in order to experience the product and gain more knowledge about it.

The relationship between consumer value systems and purchasing decisions in terms of willingness to pay and purchase quantity supports the view shared by marketing and consumer behavior scholars (Zeithaml, 1988; Lynch Jr. \& Zauberman, 2007; Sweeney, Soutar \& Mazzarol, 2008; Watson \& Spence, 2007; Penz \& Hogg, 2011; Bearden \& Etzel, 1982; Kramer \& Block, 2010). A consumer's purchasing decision, such as how much they are willing to pay for a product, how often they consume the product, and how often they purchase the product, depends on his/her value systems (Sheth et al., 1991) and the intended usage situation (Lai, 1991, Belk, 1975). This study captures the interplay between consumer value systems and the situational factors that play a role in a consumer's purchasing decision. By examining the different values consumers may assign to products, i.e., functional, symbolic, emotional, epistemic, and conditional, and 
the different usage situations consumers may be involved in, i.e., formal and informal (Morand, 1995; Belk, 1975, Luo, 2005), I expand the understanding of consumers' purchasing decisions and how they are affected by consumer value systems and the intended usage situation of the product. By highlighting the complimentary roles of consumption values and usage situations, I add important nuances to the understanding of the factors that affect consumers' purchasing decision in terms of willingness to pay and quantity purchased.

\section{2 - Theoretical Contributions}

My study shows that consumption values explain consumer purchasing decisions better, statistically, than studies that only involve one dimension of consumption values. My study has developed a framework that empirically examines how consumption values and situational factors affect consumers' purchasing decisions in terms of purchase quantity and willingness to pay. In line with the current literature, formal situations are more structured than informal situations (Morand, 1995); therefore, consumers may change their decisions according to the usage situation at hand. My study clarifies an important point: although consumers' value systems do not change, the values they perceive in a product may change in different contexts. Previous studies have, for the most part, separated consumption values and situational factors, and have not examined their effects on purchasing decisions in terms of willingness to pay and purchase quantities. Additionally, the previous literature could not study the effects of epistemic value and conditional value on consumers' decisions due to the limits of their studies. My study also considers that situational factors play a role in how consumers assign value to certain products when they are making a purchase. 
In the past, the marketing literature has thought that consumers were assigning values to products with regards to their price range (Dodds, Monroe, \& Grewal, 1991). Past studies have taken an approach that is too simplistic as they assumed that values could be measured as a uni-dimensional construct (Zeithaml, 1988, Tellis \& Gaeth, 1990); however, in my study, I have proven that consumers' value systems are more complex and multidimensional, and they aid consumers with their purchasing decisions.

In Hoon Ang's study (2000), the physical, beneficial, and image properties of products were identified and the effect of these properties on purchase intentions was examined. My study sheds light on how consumers assign values to those properties and how those values are reflected in their purchasing decisions in ways that are different from purchase intentions. Sheth et al. (1991) broke down consumer values into five dimensions and explored what those values meant to consumers and how they were assigned to certain products. In their study, only the conditional value included elements of situational factors, whereas other values are also affected by the surroundings of consumers at a specific point in time. My study has examined these effects and harmonized the relationship between these variables.

Previous literature on situational factors has also isolated the situational effects from consumer value systems. Luo (2005) examined how the presence of others in certain situations affects a consumer's purchasing decisions in terms of monetary values. Belk (1975) and Lai (1991) studied the effect of situational factors on consumer's purchasing decisions. They identified that consumers' purchasing decisions depend on the associations consumers make with the product and the consumption situation in which they intend to consume it because there is a clear relationship between the situation 
and the object, and their combinative impact on the individual's purchasing decision. In their study, they did not relate any of the situational factors to consumers' value systems, whereas my study has proven that there is a relationship between value systems, situational factors, and purchasing decisions.

This study has integrated two major dimensions that change consumers' purchasing decisions into one coherent whole. Consumers' purchasing decisions are significantly affected by these two major dimensions and by integrating themin the wine consumption context, I have made a major contribution to this complex area of consumer decision making. Sanchez-Fernandez and Iniesta-Bonillo (2007) state that scholars see multi-dimensional constructs as broad and vague and that these constructs explain less variance than uni-dimensional construct studies. However, consumers do not always decide rationally; other variables affect their decisions. This study set out to evaluate the complexities of consumer values in order to come closer to capturing the reality, and thereby come closer to explaining the complex nature of consumer decisions. As such, this study has provided further insight into consumers' purchasing decisions and the effects of consumption values on these decisions. Sanchez-Fernandez and IniestaBonillo's (2007) study also supports this view by stating that "Holbrook's typology (1996), which captures all of the economic, symbolic, hedonic, and altruistic components of perceived value, is the most comprehensive approach to the value construct, since it defines more sources of value other than other studies" (p. 441). In addition, my study also shows the moderating effect of different usage situations on consumption situations and how purchasing decisions changed as a result. Since consumers do not compare options on a single scale of preference, value, or utility (Schwartz et al., 2002), my study 
combines the values and preferences in different settings and how they affect a consumer's willingness to pay and purchase quantity.

My study sheds more light on the complex issue of consumer purchasing decisions, and the interesting and extensively studied subject of consumption values. Additionally, my study also further analyzes epistemic and conditional values, and how consumers may assign these values to certain products. My study shows how the assessment of perceived values may differ in different contexts and how these changes may result in diverse purchasing decisions. The perceived value of a product, if in line with what a consumer wants, increases consumers' willingness to pay as well as their purchase quantity. In addition, the consumption situation moderates the effect of consumption values on purchasing decisions.

\section{3 - Managerial Implications}

This study's results have several important managerial implications. A firm's success and existence rely on how well it communicates to its target audience (Slater, 1997); also, firms gain competitive advantage by offering value to their customers (Wang, 2010). An important challenge for organizations is to make sure that their product delivers the intended message. Managers need to take into account the complexity of consumers' perceptions of value (Sanchez-Fernandez \& Iniesta-Bonillo, 2007). When organizations fail to take proper account of the numerous inherent factors that form part of their product, they cannot deliver the intended message to the consumer. Thus, managers need to customize their communication strategies in order to create value for consumers. For instance, if the product is marketed for its performance, then managers need to focus their marketing effort on its functional value. Consumers need to be able to perceive the functionality of the product so that they can assign a higher functional value, 
which will be reflected in their purchasing decisions. This is also important for brand managers. Since consumers cannot usually evaluate a product before they buy and actually use it, they tend to rely on external cues such as the brand or packaging. Managers need to focus on these qualities and make sure that the product reflects its intended value. They should be able to communicate features like quality, trust, prestige, emotions, and/or novelty. For managers to properly deliver the intended value to consumers, they should be able to customize their messages according to different usage situations.

Also, in order to create symbolic value, managers need to implement a distribution strategy where their product is distributed exclusively (Pendleton, 2009). In general, consumers tend to assign higher symbolic values to products that cannot be purchased everywhere. The feeling of exclusiveness is a way for consumers to signal exclusivity to others around them. On the other hand, managers need to be aware of how their target market perceives value. For instance, Sweeney and Soutar (2001) state that "for different consumers, the components of perceived value might be differentially weighted" (p.204). The value of a product creates an important asset for companies in terms of increased purchase quantity and willingness to pay from consumers, which will be reflected in increased revenues for firms. For instance, a consumer may purchase a bottle of wine as a gift (Reyneke et al., 2011) in order to impress others by their choice of wine (Ashworth \& Matear, 2009). Even in such a scenario, it should be noted that consumers' choice of wine will differ according to where the bottle of wine will be consumed. Therefore, managers need to be able to deliver a focused message to the consumer through their promotion efforts, whether they are trying to inform the 
consumer, persuade him/her to purchase, or simply remind the consumer about the product.They need to make sure that the consumer relates the same value to the product as the firm wants them to in varying situations. For instance, the content of magazine ads shows more differences than similarities in different countries due to cultural differences. Therefore, it is the job of marketers to make sure that their products fit with society and reflect the society's culture (De Pelsmacker \& Geuens, 1998). The reason for thisis that every culture holds different belief systems and attitudes towards a specific product. Thus, the products that are most reflective of consumers' attitudes and beliefs will have a significant impact on the value that consumers assign to those products. Therefore, marketers need to provide an effective information delivering system such as advertisements, so that when two people receive the same information, they will form similar attitudes towards the product (Pendleton, 2009).

My results also suggest that consumers are willing to spend more on a certain type of wine if the product gives them pleasure, soothes them, or makes them happy. There are certain consumers who expressed their feelings regarding a product as being comfortable and relaxed. Therefore, marketers can focus on personal affective states in their promotional campaigns so that they can evoke certain feelings which would increase the perceived emotional value of their products. Managers could integrate their marketing communication strategies in order to effectively reach out to consumers and deliver the intended message by stimulating positive emotions and getting consumers to associate the positivity with the product.

Consumers like to experience new products, learn more about different things, and seek novelty in products that they are planning to purchase. Since many marketers try 
to increase the experiential content of their products (Yannopoulos, 2008), managers need to be able to create novel offerings for consumers so that consumers will appreciate the newness of the product by experiencing it. When consumers are bored with their current choices, they are likely to seek out newer versions of the product. For instance, some consumers are curious about wines they have not tried yet. Therefore, if a firm were to launch a new type of wine, it needs to be sure that the intended message of newness reaches consumers. This can be done by publishing and informing consumers in weekly wine magazines, using in-store tester booths, or employing every strategy possible to inform customers and get them to perceive the newness of the product.

Harnett (1998) and Burden (1998) suggested that retailers need to satisfy their consumers by focusing on how to deliver value and how to position the product according to its usage situation. By adjusting their strategies, marketers will have a solid value proposition for their product and will enhance their product accuracy by blending the various dimensions of consumer perceived product value (Sweeney \& Soutar, 2001; Wang, 2010). Managers should be aware that situational factors play a big role in moderating the perceived values of products; therefore, companies need to adapt their marketing strategies in order to create a consistent image so that consumers will assign the proper value to their product in every situation. In this study, situational factors are taken into consideration within the concept of the conditional values that consumers assign to products. Consumers perceive conditional value in a product when there is an emergency or a special occasion (Sheth et al., 1991). According to my study, in more informal settings, consumers may purchase a less expensive, screw cap wine, whereas for more formal situations, they are likely to purchase a more expensive bottle of wine that 
has a cork (Reyneke et al., 2011). Even in such a scenario, it should be noted that consumers' choice of wine differs according to where the product will be consumed.

Delivering the correct value to consumers is very important for firms. If organizations highlight the utility side of a product when they could be more successful highlighting the emotional aspect of it, i.e., designing a photo album that holds pictures securely with a super glue but does not take into account that consumers would not want to damage their photos if removing them, the firm may face difficulties when persuading the consumer. A firm's financial success depends on its profits, and in order to earn profits, companies need to communicate with consumers effectively through their product offerings and branding strategies. When consumers assign a higher value to products according to the five consumption values they hold, at the end they would want the product to satisfy its intended use. It does not matter if the goal was to perform well or to signal a message; in either case, if the product does its job effectively, marketers should see increased willingness to pay for their products as well as higher sales volumes.

\section{4 - Future Research \& Limitations}

My study has revealed that there is a need for continuing research into the conceptualization of perceived value and consumption situations. My study has focused on formal situations and how they affect consumption values in these contexts. There is a need for studies that analyze the relationship between different situational factors and this multi-dimensional construct in order to further enhance our understanding of how other context cues affect consumers' decisions.

Secondly, for the purpose of my study, I focused on purchase quantity and willingness to pay in terms of purchasing decisions. Future studies could look further into the different aspects of purchasing decisions such as purchase frequency of consumers or 
the overall purchase decision process. In addition, future research could include the situational factors within consumers' decision-making processes and show how these factors trigger different actions.

My study has only looked at consumer's purchasing decisions at the point when

they are actually deciding to purchase the product. Future studies could further look into how different usage situations play different roles in pre-purchase or post-purchase scenarios. For instance, the consequence of using a product could be a very significant factor in determining how usage changes the perceived value of the product (Sweeney \& Soutar, 2001). The intended usage situation can also affect how the product helps consumers satisfy their goal, which can change the perceived value as well.

Additionally, future research could look further into cross-cultural differences (Grunert \& Scherhorn, 1990; Overby, Gardial, \& Woodruff, 2004) within the context of different products and how consumers from different backgrounds perceive differences in the semantic meanings of value, especially the role of ethical and spiritual value components (Sanchez-Fernandez \& Iniesta-Bonillo, 2007).

The data collected for this study is based on a mailed survey. The responses I received from participants may not clearly reflect the actual decisions they make. To further improve this study, the data could be gathered by observation. An observation method might give more accurate results, although consumers who are observed may behave differently than normally.

\section{5 - Conclusion}

It is well established that consumption values play a significant role in purchasing decisions. My study unveils the influence of consumption values and consumption situations on purchasing decisions. I studied wine products since wine products are 
experiential (Mueller, Lockshin, \& Louviere,2010) and can be purchased in different price ranges, as well as having different features such as texture, aroma, and packaging. My study integrates two rarely studied dimensions of consumption values: epistemic and conditional values. It is also important that specific situational factors have an effect on how consumers assign value to products and how these assigned values lead to different levels of willingness to pay and different purchase quantities. My study has contributed to the existing literature by analyzing the direct effect of four consumption values on consumers' purchasing decisions and by integrating the fifth consumption value in terms of usage situations and checking for its indirect effect on purchasing decisions. I have also studied purchase decisions in terms of willingness to pay and quantity of purchase, whereas previous studies have not considered actual purchase decisions in this manner.

By integrating various usage situations and consumers' value systems, and showing their direct and indirect effects on consumer purchase decisions, my study sheds some light on the complexities of consumers' decision-making processes. 


\section{REFERENCES}

Aiken, L. S. and West, S. G. 1991. Multiple regression: Testing and interpreting interactions. Newbury Park, CA: Sage Publishing.

Ainslie, A., and Rossi, P. E. 1998. Similarities in choice behavior across product categories. Marketing Science 17(2): 91-107.

Anderson, J. C. and Gerbing, D. W. 1988. Structural equation modeling in practice: A review and recommended two-step approach. Psychological Bulletin103(3): 411423.

Ashworth, L., and Matear, M. 2009. The impact and accuracy of beliefs relating to impressions caused by products. Advances in Consumer Research 8: 128-129.

Atalay, A. S. and Meloy, M. G. 2011. Retail therapy: A strategic effort to improve mood. Psychology and Marketing 28(6): 638-659.

Atinc, G., Simmering, M. J., and Kroll, M. J. 2011. Control variable use and reporting in macro and micro management research. Organizational Research Methods 15(1): $57-74$.

Babin, B. J., Darden, W. R., and Griffin, M. 1994. Work and/or fun: Measuring hedonic and utilitarian shopping. Journal of Consumer Research 20(4): 644-700.

Bagozzi, R. P. and Yi, Y. 1988. On the evaluation of structural equation models. Academy of Marketing Science 16(1): 74-94.

Banks, P. A. 2010. Conceptions of art ownership as a form of wealth accumulation among the black middle-class. Quality Sociology 33(July): 333-348.

Bargh, J. A. 2002. Losing consciousness: Automatic influences on consumer judgment, behavior, and motivation. Journal of Consumer Research 29(2): 280-285. 
Barlow, J., and Maul, D. 2000. Emotional value: Creating strong bonds with your customers. San Francisco, CA: Berrett-Koehler Publishers, Inc.

Basu, A. K., and Hicks, R. L. 2008. Label performance and the willingness to pay for fair trade coffee: A cross-national perspective. International Journal of Consumer Studies 32: 470-478.

Baumeister, R. F. 2002. Yielding to temptation: Self-control failure, impulsive purchasing, and consumer behavior. Journal of Consumer Research 28(4): 670676.

Bearden, W. O., and Etzel, M. J. 1982. Reference group influence on product and brand purchase decisions. Journal of Consumer Research 9(September): 183-194.

Belk, R. W. 1974. An exploratory assessment of situational effects in buyer behavior. Journal of Marketing Research 11(2): 156-163.

Belk, R. W. 1975. Situational variables and consumer behavior. Journal of Consumer Research 2(December):157-164.

Benfratello, L., Piacenza, M., and Sacchetto, S. 2009. Taste or reputation: What drives market prices in the wine industry? Estimation of a hedonic model for Italian premium wines. Applied Economics 41: 2197-2209.

Bergkvist, L. and Rossiter, J. R. 2007. The predictive validity of multiple-item versus single-item measures of the same constructs. Journal of Marketing Research 44: $175-184$.

Berthon, P., Pitt, L. F., and Campbell, C. 2009. Does brand meaning exist in similarity or singularity? Journal of Business Research 62(3): 356-361. 
Bertini, M., Ofek, E., and Ariely, D. 2009. The impact of add-on features on consumer product evaluations. Journal of Consumer Research 36(1): 17-28.

Bettman, J. R. and Zins, M. A. 1977. Constructive processes in consumer choice.Journal of Consumer Research 4: 75-85

Biehal, G. and Chakravarti, D. 1986. Consumers' use of memory and external information in choice: Macro and micro perspectives. Journal of Consumer Research, 12(4): 382-405

Blake, B. F., Zenhausern, R., Perloff, R., and Heslin, R. 1973. The effect of intolerance of ambiguity upon product perceptions. Journal of Applied Psychology 58(2): 239243.

Böcker, F. 1986. Children's influence on their mothers' preferences. A new approach. International Journal of Research in Marketing 3: 39-52.

Bolton, R. N. and Drew, J.H. 1991. A multistage model of customers' assessments of service quality and value. Journal of Consumer Research 17(4): 375-384.

Bonatti, A.2011. Brand-specific tastes for quality. International Journal of Industrial Organization 29: 562-575.

Bosmans, A. 2006. Scents and sensibility: When do (in)congruent ambient scents influence product evaluations. American Marketing Association 70(July): 32-43.

Bui, M., Krishnen, A. S., and Bates, K. 2009. Modeling regret effects on consumer postpurchase decisions. European Journal of Marketing 45(7/8): 1068-1090.

Burden, S. 1998. Current trends and issues in the retail sector. European Venture Capital Journal, November: November: 1-5. 
Burnett, M. S.and Lunsford, D. A. 1994. Conceptualizing guilt in the consumer decisionmaking process. The Journal of Consumer Marketing 11:33-43.

Champion, J. C., Hunt, J. B., and Hunt, T. G. 2010. The effect of retail store image on student perceptions of merchandise quality and willingness to buy. American Journal of Business Research 3(1): 17-32.

Chen, T. Y., Chang, P.L., and Chang, H. S. 2005. Price, brand cues and banking customer value. The International Journal of Bank Marketing. 23: 273-291.

Chow, S., Celsi, R. L., and Abel, R. 1990. The effects of situational and intrinsic sources of personal relevance on brand choice decisions. Advances in Consumer Research 17: $755-759$.

Corfman, K. P., Lehman, D. R., and Narayanan, S. 1991. Values, utility, and ownership: Modeling the relationships for consumer durables. Journal of Retailing 67(2): 184-204.

Das, E., Vermeulen, I., Laagland, T., and Postma, A. 2010. When you are what you own. International Journal of Advertising 29(5): 795-813.

D’Astous, A., Bensouda, I., and Guindon, J. 1989. A re-examination of consumer decision making for a repeat purchase product: Variations in product importance and purchase frequency. Advances in Consumer Research 16(1): 433-438.

De Bruyn, A., and Lilien, G. L. 2005. A multi stage model of word-of-mouth influence through viral marketing. International Journal of Research in Marketing 25: 151163.

De Pelsmacker, P., and Geuens, M. 1998. Reactions to different types of ads in Belgium and Poland. International Marketing Review 15(4): 277-290. 
De Pelsmacker, P., Janssens, W., Sterckx, E., and Mielants, C. 2005. Consumer preferences for marketing of ethically labelled coffee. International Marketing Review 22(5): 512-530.

Depositario, D. P. T., Nayga, Jr., R. M., Wu, X., and Laude, T. P. 2009. Effects of information on consumers' willingness to pay for golden rice. Asian Economic Journal 23(4): 457-476.

Dillman, D. A. 1978. Mail and telephone surveys: The total design method New York, NY: Wiley.

Dodds, W. B., Monroe, K. B., and Grewal D. 1991. Effects of price, brand, and store information on buyers' product evaluations. Journal of Marketing Research 28(3): 307-319.

Dube, L., Cervellon, M. C., and Jingyuan, H. 2003. Should consumer attitudes be reduced to their affective and cognitive bases? Validation of a hierarchical model. International Journal of Research In Marketing 20: 259-272.

Eastman, J. K. and Eastman, K. L. 2011. Perceptions of status consumption and the economy. Journal of Business \& Economics Research 9(7): 9-19.

Eastman, J. K., Goldsmith, R. E., and Flynn, L. R. 1999. Status consumption in consumer behavior: Scale development and validation. Journal of Marketing Theory and Practice 7: 41-52.

Ferber, R. 1973. Consumer economics - Survey. Journal of Economic Literature 11(4): 1303-1342.

Fitzsimons, G. J., Hutchinson, J. W., Williams, P., Alba, J. W., Chartrand, T. L., Huber, J., Kardes, F. R., Menon, G., Raghubir, P., Russo, J. E., Shiv, B., and Tavassoli, 
N. T. 2002. Non-conscious influences on consumer choice. Marketing Letters 13(3): 269-279.

Flint, D. J., Woodruff, R. B., and Gardial, S. F. 1997. Customer value change in industrial marketing relationships: A call for new strategies and research, Industrial Marketing Management 26(2): 163-237.

Ford, J. B., and Merchant, A. 2010. Nostalgia drives donations. The power of charitable appeals based on emotions and intentions. Journal of Advertising Research (December): 450-459.

Fornell, C. and Larcker, D. F. 1981. Evaluating structural equation models with unobservable variables and measurement error. Journal of Marketing Research 18: $39-50$.

Gao, Z., Schroeder, T. C., and Yu, X. 2010. Consumer willingness to pay for cue attribute: The value beyond its own. Journal of International Food \& Agribusiness Marketing 22: 108-124.

Gerbing, D. W. and Anderson, J. C. 1988.An updated paradigm for scale development incorporating unidimensionality and its assessment. Journal of Marketing Research 25(2): 186-192.

Goodwin, C. 1992. Good guys don't wear polyester: Consumption ideology in a detective series. Advances in Consumer Research 19(1): 739-746.

Grapentine, T. H., and Weaver, D. A. 2009. What really affects behavior? Marketing Research 12(Winter): 13-17. 
Graham, M. E., and Bansal, P. 2007. Consumers' willingness to pay for corporate reputation: The context of airline companies. Corporate Reputation Review 10(3): 189-200.

Grewal, D., and Baker, J. 1994. Do retail store environmental factors affect consumers' price acceptability? An empirical examination. International Journal of Research in Marketing 11: 107-115.

Grunert, S. C. and Scherhorn, G. 1990. Consumer values in West Germany underlying dimensions and cross-cultural comparison with North America. Journal of Business Research 20: 97-107.

Hartnett, M. 1998. Shopper needs must be priority. Discount Store News, Retrieved from http://findarticles.com/p/articles/mi_m3092/is_n9_v37/ai_n27532867/.

Han, S., Lerner, J. S., and Keltner, D. 2007. Feelings and consumer decision making: The appraisal-tendency framework. Journal of Consumer Psychology 17(3): 158-168.

Heaney, J., Goldsmith, R. E., and Jusoh, W. J. W. 2005. Status consumption among Malaysian consumers: Exploring its relationships with materialism and attentionto-social-comparison-information. Journal of International Consumer Marketing 17(4): 83-98.

Heitmann, M., Lehmann, D. R., and Herrmann, A. 2007. Choice goal attainment and decision and consumption satisfaction. Journal of Marketing Research 44 (May): 234-250.

Hirschman, E. C. 1980. Innovativeness, novelty seeking, and consumer creativity. Journal of Consumer Research 7(3): 283-295. 
Hirschman, E. C., and Holbrook, M. B. 1982. Hedonic consumption: Emerging concepts, methods and propositions. The Journal of Consumer Research 9(2): 132-140.

Holbrook, M. B. 1996. Customer value - a framework for analysis and research. Advances in Consumer Research 23: 138-142.

Hoon Ang, S. 2000. The influence of physical, beneficial and image properties on responses to parallel imports. International Marketing Review 17(6): 509-524.

Houston, M. J. and Rothschild, M. L. 1978. Conceptual and methodological perspectives by self-report. Journal of Marketing, 35: 48-53.

Howard, J. A., and Sheth, J. N. (1969). The theory of buyer behavior. John Wiley and Sons.

Huneke, M. E., Cole, C., and Levin, I. P. 2004. How varying levels of knowledge and motivation affect search and confidence during consideration and choice. Marketing Letters 15(2-3): 67-79.

Inman, J. J., Winer, R. S., and Ferraro, R. 2009. The interplay among category characteristics, customer characteristics, and customer activities on in-store decision making. Journal of Marketing 73(September): 19-29.

Iyengar, S. S. and Lepper, M. R. 1999. Rethinking the value of choice: A cultural perspective on intrinsic motivation. Journal of Personality and Social Psychology 76(3): 349-366.

Jonassen, C. T. 1959. Contributions of sociology to marketing. Journal of Marketing 24(2): 29-38. 
Kaltcheva, V. D., and Weitz, B. A. 2006. When should a retailer create an exciting store environment? Journal of Marketing 70 (January): 107-118.

Kemp, E., and Kopp, S. W. 2011. Emotion regulation consumption: When feeling better is the aim. Journal of Consumer Behavior 10: 1-7.

Khalifa, A. S. 2004. Customer value: A review of recent literature and an integrative configuration. Management Decision 45(5/6): 645-710.

Kotler, P. 1974. Atmospherics as a marketing tool. Journal of Retailing 49(4): 48-64.

Kramer, T., and Block, L. 2010. Nonconscious effects of peculiar beliefs on consumer psychology and choice. Journal of Consumer Psychology 21: 101-111.

Kirhsnamurthi, L., and Raj, S. P. 1988. A model of brand choice and purchase quantity price sensitivities. Marketing Science 7(1): 1-20.

Kropp, F., Lavack, A. M., and Silvera, D. H. 2005. Values and collective self-esteem as predictors of consumer susceptibility to interpersonal influence among university students. International Marketing Review 22(1): 7-33.

Lai, A. W. 1991. Consumption situation and product knowledge in the adoption of a new product. European Journal of Marketing 25(0): 55-67.

Lapierre, J. 2000. Customer-perceived value in industrial contexts. The Journal of Business \& Industrial Marketing 15(2/3): 122-162.

Lefkoff-Hagius, R., and Mason, C. H. 1993. Characteristic beneficial, and image attributes in consumer judgments of similarity and preference. Journal of Consumer Research 20(June): 100-110. 
Leskosek-Cukalovic, I., Despotovic, S., Nedovic, V., Lakic, N., and Niksic, M. 2010. New type of beer-- Beer with improved functionality and defined pharmacodynamics properties. Food Technology Biotechnology 48(3): 384-391.

Liebenstein, H. 1950. Bandwagon, snob, and Veblen effects in the theory of consumers' demand. Quarterly Journal of Economics 64(2): 183-207.

Lilly, B. 2001. Assessing the accuracy of purchase quantity decisions. The Marketing Management Journal 11(2): 58-66.

Lopes, A. B., and Galletta, D. F. 2006. Consumer perceptions and willingness to pay for intrinsically motivated online content. Journal of Management Information Systems 23(2): 203-231.

Loulakis, A., and Hill, R. P. 2010. Status and materialism among college-aged women. American Marketing Association (Winter): 45-52.

Luna, D., and Gupta, S. F. 2001. An integrative framework for cross-cultural consumer behavior. International Marketing Review 18(1): 45-69.

Luo, X. 2005. How does shopping with others influence impulsive purchasing? Journal of Consumer Psychology 15(4): 288-294.

Lutz, R., and Kakkar, P. 1975. The psychological situation as a determinant of consumer behaviour. Advances in Consumer Research 2(1): 439-453.

Lynch Jr., J. G., and Zauberman, G. 2007. Construing consumer decision making. Journal of Consumer Psychology 17(2): 107-112.

MacKay, H. 1999. Turning point: Australians choosing their future. Sydney: Pan Macmillan. 
Mathwick, C., Malhotra, N. and Rigdon, E. 2001. Experiential value: Conceptualization, measurement, and application in the catalog and internet shopping environment. Journal of Retailing 77(1): 39-56.

Mattsson, J. 1992. A service quality model based on an ideal value standard. International Journal of Service Industry Management 3(3): 18-33.

Meyer, R. J., Zaho, S., and Han, J. K. 2008. Biases in valuation vs. usage of innovative product features. Marketing Science 27(6): 1083-1096.

Mizerski, R. W. and White, J. D. 1986. Understanding and using emotions in advertising. The Journal of Consumer Marketing 3: 57-69.

Moav, O., and Neeman, Z. 2010. Status and poverty. Journal of the European Association 8(2-3): 413-420.

Morand, D. A. 1995. The role of behavioral formality and informality in the enactment of bureaucratic versus organic organizations. Academy of Management Review 20(4): 831-872.

Morton, L. P. 2000. Segmenting by neighborhoods. Public Relations Quarterly (Fall): 42-43.

Moschis, G. P. 1976. Social comparison and informal group influence. Journal of Marketing Research 13(August): 237-244.

Mueller, S., Lockshin, L., and Louviere, J. J. 2010. What you see may not be what you get: Asking consumers what matters may not reflect what they chose. Marketing Letters 21:335-350.

Munsinger, G. M., Weber, J. E., and Hansen, R. W. 1975. Joint home purchasing decisions by husbands and wives. Journal of Consumer Research 1(4): 60-66. 
Naald, B. V., and Cameron, T. A. 2011. Willingness to pay for other species' well-being. Ecological Economics 70(January): 1325-1335.

Narayan, V., Rao, V., and Saunders, C. 2011. How peer influence affects attribute preferences: A Bayesian updating mechanism. Marketing Science 30(2): 368-384.

Neal, D. T., Wood, W., and Quinn, J. M. (2006). Habits: A repeat performance. Current Directions in Psychology Science, 15: 198-202.

Netemeyer, R. G., Bearden, W. O., and Teel, J. E. 1992. Consumer susceptibility to interpersonal influence and attributional sensitivity. Psychology \& Marketing 9(5): 379-394.

Nunes, J. C. 2009. Status: Why consumers engage in conspicuous consumption and how they may be perceived. Advances in Consumer Research 36: 12-15.

O'Cass A., and McEwen, H. 2004. Exploring consumer status and conspicuous consumption. Journal of Consumer Behavior 4(1): 25-39.

Osgood, C. E., Suci, G. J., and Tannenbaum, P. H. 1957. The measurement of meaning. Urbana, IL: University of Illinois Press.

Overby, J. W., Gardial, S. F., and Woodruff, R. B. 2004. French versus American consumers' attachment to value to a product in a common context: A crossnational comparison. Journal of the Academy of Marketing Science 32(4): 437460.

Oxoby, R. J. and Finnigan, H. Developing heuristic-based quality judgments: Blocking in consumer choice. Psychology \& Marketing 24(4): 295-313. 
Parasuraman, A. and Grewal, D. 2000. The impact of technology on the quality-valueloyalty chain: A research agenda. Journal of the Academy of Marketing Science 28(1): 168-242.

Park, C. W., Jaworski, B. J., and MacInnis, D. J. 1986. Strategic brand concept/image management. Journal of Marketing 50:135-145.

Park, E. J., Kim, E. Y., and Forney, J. C. 2006. A structural model of fashion-oriented impulse buying behavior. Journal of Fashion Marketing and Management 10: 433-446.

Park, W. W., and Yanos, A. A. 2006. Treaty obligations and national law: Emerging conflicts in international arbitration. Hastings Law Journal 58(2): 251 -+.

Pendleton, G. C. M. 2009. An empirical analysis of the dimensions of consumer value for an experiential offering in marketing. (April):1-159.

Penz, E., and Hogg, M. K. 2011. The role of mixed emotions in consumer behavior. European Journal of Marketing 45(1/2): 104-132.

Posakoff, P. M., MacKenzie, S. B., Lee, J. Y., and Posakoff, N. I. 2003. Common method biases in behavioral research: A critical review of the literature and recommended remedies. The Journal of Applied Psychology 88: 879-903.

Posavac, S. S., Hernzenstein, M., and Sanbonmatsu, D. M. 2003. The role of decision importance and the salience of alternatives in determining the consistency between consumers' attitudes and decisions. Marketing Letters 14(1): 47-57.

Power, K. and Mont, O. 2010. The role of formal and informal forces in shaping consumption and implications for sustainable society: Part II. Sustainability 2:2573-2592. 
Putsis W. P., and Srinivasan, N. 1994. Buying or just browsing? The duration of purchase deliberation. Journal of Marketing Research 31 (August 1994): 393-402.

Quester, P. G., and Smart, J. 1998. The influence of consumption situation and product involvement over consumers' use of product attribute. Journal of Consumer Marketing 15(3): 220-238.

Rawwas, M. Y. A., Rajendran, K. N., and Wuehrer, G. A. 1996. The influences of worldmindedness and nationalism on consumer evaluation of domestic and foreign products. International Marketing Review 13(2) 20-38.

Reyneke, M., Berthon, P. R., Pitt, L. F., and Parent, M. 2011. Luxury wine brands as gifts: Ontological and aesthetic perspectives. International Journal of Wine Business Research 23(3): 258-270.

Richins, M. L., Bloch, P. H., and McQuarrie, E. F. 1992. How enduring and situational involvement combine to create involvement responses. Journal of Consumer Psychology 1(2): 143- 153.

Rokeach, M. 1973. The nature of human values. John Wiley, NY: NY.

Rook, D. W., Fisher, R. J. 1995. Normative influences on impulsive buying behavior. Journal of Consumer Research 22(3): 305-313.

Rucker, D. D., and Galinsky, A. D. 2008. Desire to acquire: Powerlessness and compensatory consumption. Journal of Consumer Research 35(August): 257-267.

Saad, L. 2006. Christmas shoppers appear to be in a jolly mood. Gallup Poll Briefing (November): 1-3.

Sampson, D. L. and Smith, H. P. 1957. A scale to measure worldminded attitudes. The Journal of Social Psychology. 45: 99-106. 
Sanchez-Fernandez, R. and Iniesta-Bonillo, M. A. 2007. The concept of perceived value: A systematic review of the research. Marketing Theory 7(4): 427-451.

Schupp, A., Gillespie, J., O’Neil, C. E., Prinyawiwatkul, W., and Makienko, I. 2005. The impact of an exotic label on consumer willingness to taste, test, purchase, and price a new meat product. Journal of Food Distribution Research 36(2): 50-60.

Schwartz, B., Ward, A., Monterosso, J., Lyubomirsky, S., White, K., and Lehman, D. R. 2002. Maximizing versus satisficing: Happiness is a matter of choice. Journal of Personality and Social Psychology. 83(5): 1178-1197.

Schwartz, S. H. 1994. Are there universal aspects in the structure and contents of human values? Journal of Social Issues, 50(4): 19-46.

Sheth, J. N., Newman, B. I., and Gross, B. L. 1991. Why we buy what we buy: A theory of consumption values. Journal of Business Research 22(2): 159-170.

Shukla, P. 2009. Status consumption in cross-national context. International Marketing Review 27(1): 108-129.

Shuttleworth, M. 2008. Research variables. Retrieved on January 30, 2012 from Experiment Resources: http://www.experiment-resources.com/researchvariables.html.

Silayoi, P., and Speece, M. 2007. The importance of packaging attributes: A conjoint analysis approach. European Journal of Marketing 41(11/12): 1495-1517.

Slater, S.F. 1997. Developing a Customer Value-Based Theory of the Firm. Journal of the Academy of Marketing Science 25(2): 162-169.

Spetic, W., Kozak, R., and Cohen, D. 2004. Willingness to pay and preferences for healthy home attributes in Canada. Forest Products Journal 55(10): 19-24. 
Spiro, R. L. 1983. Persuasion in family decision-making. Journal of Consumer Research 9(March): 393- 402.

Srivastava, R. K., Alpert, M. I., and Shocker, A. D. 1984. A customer-oriented approach for determining market structures. Journal of Marketing 48(Spring): 32-45.

Strausz, R. 2009. Planned obsolescence as an incentive device for unobservable quality. The Economic Journal 119 (October): 1405-1421.

Steenkamp, J. E. M., Heerde, H. J. V., and Geyskens, I. 2010. What makes consumers willing to pay a price premium for national brands over private labels. Journal of Marketing Research 47(December): 1011-1024.

Steenkamp, J. E. M., and Jong M. G. 2010. A global investigation into the constellation of consumer attitudes toward global and local products. American Marketing Association 74 (November): 18-40.

Sweeney, J. C. and Soutar, G. N. 2001. Consumer perceived value: The development of a multiple item scale. Journal of Retailing 77:203-220.

Sweeney, J. C., Soutar, G. N., and Mazzarol, T. 2008. Factors influencing word of mouth effectiveness: Receiver perspectives. European Journal of Marketing 42(3/4): 344-364.

Tellis, G. J. and Gareth, G. J. 1990. Best value, price-seeking, and price aversion: The impact of information and learning on consumer choices. Journal of Marketing 54(2): 34-45.

Thaler, R. 1985. Mental accounting and consumer choice. Marketing Science 4(3): 199214. 
Thomas, W. I. 1927. The behavior pattern and the situation. American Sociological Society 22: 1-13.

Thompson, D. V. and Norton, M. I. 2011. The social utility of feature creep. Journal of Marketing Research 48(3): 555-565.

Triandis, H. C. 1994. Social Psychology; culture; cross-cultural studies. New York, NY: McGraw-Hill.

Tsai, S. 2005. Impact of personal orientation on luxury-brand purchase value. International Journal of Market Research 47(4): 429-454.

Tsiros, M., and Mittal, V. 2000. Regret: A model of its antecedents and consequences in consumer decision making. The Journal of Consumer Research 26(4): 401-417.

Udell, J. G. 1965. Can attitude measurement predict consumer behavior? Journal of Marketing 29(October): 46-50.

Umberger, W. J., Boxall, P. C., and Lacy, R. C. 2009. Role of credence and health information in determining US consumers' willingness to pay for grass finished beef. The Australian Journal of Agricultural and Resource Economics 53(4): 603623.

Van Osselaer, S. M. J., Ramanathan, S., Campbell, M., Cohen, J. B., Dale, J. K., Herr, P. M., Janiszewski, C., Kruglanski, A. W., Lee, A. Y., Read, S. J., Russo, J. E., and Tavassoli, N. T. 2005. Choice based on goals. Marketing Letters 16(3/4): 335346.

Wang, E. S. 2010. Impact of multiple perceived value on consumers' brand preference and purchase intention: A case of snack foods. Journal of Food Products Marketing 16: 386-397. 
Wang, Q. and Xie, J. 2011. Will consumers be willing to pay more when your competitors adopt your technology? The impacts of the supporting-firm base in markets with network effects. Journal of Marketing 75(September): 1-17.

Watson, L., and Spence, M. T. 2007. Causes and consequences of emotions on consumer behavior. European Journal of Marketing 41(5/6): 487-511.

White, K., and Dahl, D. W. 2006. To be or not to be? The influence of dissociative reference groups on consumer preferences. Journal of Consumer Psychology 16(4): 404-414.

Wood, W., and Neal, D. T. 2007. A new look at habits and the habit-goal interface. Psychological Review, 114: 842-862.

Wood, W., and Neal, D. T. 2009. The habitual consumer. Journal of Consumer Psychology19(2009): 579-592.

Woodruff, R. B. and Gardial, S. F. 1996. Know your customer. New approaches to understanding customer value and satisfaction, Cambridge: Blackwell Publishers, Inc.

Yannopoulos, P. 2008. Marketing Strategy. Toronto, ON: Nelson Education Ltd.

Yen, H. R., and Chuang, S. C. 2008. The effect of incidental affect on preference for the status quo. Journal of the Academy of Marketing Science 36(2008): 522-537.

Zauberman, G., Ratner, R. K., and Kim, B. K. 2008. Memories as assets: Strategic memory protection in choice over time. Journal of Consumer Research 35(February): 715-728.

Zeithaml, V. A. 1988. Consumer perceptions of price, quality, and value: A means-end model and synthesis of evidence. Journal of Marketing 52(July): 2-22. 